\title{
Principal Resonance Contributors to High-Valent, Transition-Metal Alkylidene Complexes
}

\author{
Thomas R. Cundari and Mark S. Gordon* \\ Contribution from the Department of Chemistry, North Dakota State University, \\ Fargo, North Dakota 58105-5516. Received November 8, 1990
}

\begin{abstract}
The results of ab initio calculations are reported for prototypical high-valent, alkylidene complexes. Stationary points on each potential energy surface are characterized and compared to experimental information where available; as long as a suitably flexible valence basis set is used, good agreement between theoretically calculated and experimentally determined geometries is obtained. The complexes of interest include group IVB ( $\mathrm{Ti}, \mathrm{Zr}$ and $\mathrm{Hf}$ ) and group $\mathrm{VB}(\mathrm{Nb}$ and $\mathrm{Ta}$ ) alkylidenes with hydride ligands as well as models for the four-coordinate, olefin metathesis catalysts (Mo-, W-, and Re-alkylidenes) which have been recently synthesized and characterized. In light of the fact that much of the discussion concerning the reactivity of transition-metal carbene complexes has been presented in terms of the resonance contributors derived from rearranging the electrons in the $\mathrm{M}-\mathrm{C} \sigma$ and $\pi$ orbitals, the minima obtained from the first portion of the study are then subjected to a further procedure to calculate these contributions. Resonance structures in which the carbon is the negative end of the $\mathrm{M}-\mathrm{C}$ bond (i.e., nucleophilic resonance structures) contribute $50 \%$ to the ground-state wave function of these complexes. Those in which the carbon is formally neutral account for much of the remainder (45\%). Only $5 \%$ is comprised of electrophilic resonance structures, i.e., those in which the carbon is the positive end of the $\mathrm{M}-\mathrm{C}$ bond. Furthermore, the metal-carbon double bond is predominantly comprised of five resonance structures. Four of these resonance structures correspond to models of carbene bonding which have been discussed previously in the literature. The other resonance structure, which contributes roughly $33 \%$ to the ground-state wave function, has hitherto not been considered when examining the chemical reactivity of carbenes. This large resonance contributor can be described as arising from a dative carbon-to-metal $\sigma$ bond plus a covalent $\mathrm{M}-\mathrm{C} \pi$ bond.
\end{abstract}

\section{Introduction}

Transition-metal alkylidene (or carbene) complexes have been the focus of intense experimental ${ }^{1-5}$ and theoretical ${ }^{6-21}$ research

(1) Mayer, J. M.: Nugent, W. A. Metal-Ligand Multiple Bonds; Wiley: New York, 1989

(2) Transition Metal Carbene Complexes; Dotz, K. H., Ed.; Verlag: Weinheim, 1983.

(3) Collmann, J. P.; Hegedus, L. S.; Norton, J. R.; Finke, R. G. Principles and Applications of Organotransition Metal Chemistry; University Science Books: Mill Valley, 1987

(4) Schrock, R. R. Acc. Chem. Res. 1979, 12, 98.

(5) (a) Brown, F. J. Prog. Inorg. Chem. 1980, 27, 1. (b) Schubert, U Coord. Chem. Rev. 1984, 55, 261.

(6) (a) Hoffmann, R.; Jemmis, E.: Goddard, R. J. J. Am. Chem. Soc. 1980, 102, 7667. (b) Hoffmann, R.; Eisenstein, O.; Rossi, R. J. Am. Chem Soc. $1981,103.82$

(7) (a) Hall, M. B.; Taylor, T. E. J. Am. Chem, Soc, 1984, 106, 1576, (b) Hall, M. B. In Ouantum Chemistry: The Challenge of Transition Metals and Coordination Chemistry; Veillard, A., Ed.; Reidel: Dordrecht, 1986; p 319.

(8) Hoffman, $P$. in ref $2, p 114$

(9) (a) Ushio, J.; Nakatsuji, H;; Yonezawa, T. J. Am. Chem. Soc. 1983 105, 426. (b) Ushio, J.; Nakatsuji, H.; Yonezawa, T. J. Am. Chem. Soc. 1984, 106, 5892.

(10) (a) Vincent, M. A.; Yoshioka, Y.; Schaefer, H. F. J. Phys. Chem. 1982, 86, 3905. (b) Brooks, B.; Schaefer, H. F. Mol. Phys. 1977, $34,193$. (c) Brooks, B.; Schaefer, H. F. Int. J. Quantum Chem. 1978, 14, 603.

(11) Alvardo-Swaisgood, A. E.; Harrison, J. F. J. Mol. Struct. (THEOCHEM 1988, 169, is5.

(12) (a) Francl, M. M.; Pietro, W. J.; Hout, R. F.; Hehre, W. J. Organometallics 1983, 2, 281. (b) Francl, M. M.; Hehre, W. J. Organometallics 1983, 2, 457. (c) Francl, M. M.; Pietro, W. J.; Hout, R. F.; Hehre, W. J. Organometallics 1983, 2, 815. (d) Hout, R. F.; Pietro, W. J.; Hehre, W. J. A Pictorial Approach to Molecular Structure and Reactivity; Wiley: New York, 1984; $p 149$.

(13) Block, T. F.; Fenske, R. F.; Casey, C. P. J. Am. Chem. Soc. 1976, 98,441 .

(14) Kostic, N. M.; Fenske, R. F. J. Am. Chem. Soc, 1982, 104,3879

(15) Spangler, D.; Wendoloski, J. J.; Dupuis, M.; Chen, M. M. L.; Schaefer, H. F. J. Am. Chem. Soc. 1981, 103, 3985.

(16) (a) Carter, E. A.; Goddard, W. A. J. Am. Chem. Soc. 1986, 108, 2180. (b) Carter, A.; Goddard J. Phys. Chem. 1984, 88, 1485. (c) Carter, E. A.; Goddard, W. A. J. Am. Chem. Soc, 1987, 109, 579. (d) Carter, E. A Goddard, W. A. Organometallics 1988, 7,675. 1993.

Marynick, D. S.; Kirkpatrick, C. M. J. Am. Chem. Soc. 1985, 107,

(18) Mintz, E. A.; Gregory, A. R. J. Am. Chem. Soc. 1985, 107, 2179 (19) (a) Goddard, W. A.; Rappe, A. K. J. Am. Chem. Soc. 1977, 99, 3966 (b) Goddard, W. A.: Rappe, A. K. J. Am. Chem. Soc. 1980, 102, 5114 . (c) Goddard, W. A.; Rappe, A. K. J. Am. Chem. Soc. 1982, 104, 297. (d) Goddard, W. A.; Rappz, A. K. J. Am. Chem. Soc. 1982, 104, 448. efforts. Carbene complexes $\left(L_{n} M=C(R) R^{\prime}\right)$ have been implicated as intermediates and reactive species in a wide range of important heterogeneous and homogeneous catalytic reactions ranging from olefin metathesis ${ }^{22-26}$ (eq 1) and biochemical oxidation ${ }^{27,28}$ to the

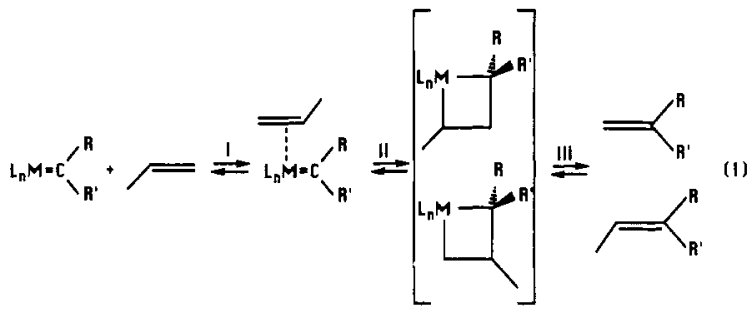

Fischer-Tropsch ${ }^{3,29}$ synthesis (the reduction of $\mathrm{CO}$ by $\mathrm{H}_{2}$ to various organics, including alkanes, over heterogeneous transition-metal catalysts). Carbene complexes are typically subdivided into two broad groups. In the first group the ligated carbene carbon typically possesses heteroatom substituents (e.g. X, Y = $\mathrm{OR}, \mathrm{NR}_{2}$, etc.) or aryl groups directly attached to the carbene carbon. These carbenes are referred to as Fischer-type carbenes. ${ }^{2}$ Fischer-type carbenes act as electrophiles in chemistry directed

(20) (a) Upton, T. H.; Rappe, A. K. J. Am. Chem. Soc. 1985, 107, 1206. (b) Upton, T. H.; Rappe, A. K. Organometallics 1984, 3, 1440.

(21) Sodupe, M.; Lluche, J. M.; Oliva, A.; Bertran, J. Organometallics $1989,8,1837$

(22) (a) Grubbs, R. H. In Comprehensive Organometallic Chemistry; Wilkinson, G., Stone, F. G. A., Abel, E. W., Eds.; Pergamon: Oxford, 1982; Vol. 8, p 499. (b) Grubbs, R. H. Adv. Inorg. Chem. 1978, 24, 1.

(23) (a) Schrock, R. R. J. Organomet. Chem. 1986, 300, 249. (b) Schrock, R. R. Acc. Chem. Res. 1990, 23, 158 .

(24) Katz, T. J. Adv. Organomet. Chem. 1977, 16, 283.

(25) Herrison, J. L.; Chauvin, Y. Makromol. Chem. 1970, 141, 161.

(26) Calderon, N.; Lawrence, J. P.; Ofstead, E. A. Adv. Organomet. Chem. $1979,17,449$.

(27) Cytochrome P-450; Ortiz de Montellano, P. R., Ed.; Plenum: New York, 1986.

(28) Chevrier, B.; Weiss, R.; Lange, M.; Chottard, J. C.; Mansuy, D. J. Am. Chem. Soc. 1981, 103, 2899.

(29) (a) Rofer-DePoorter, C. K. Chem. Rev. 1981, 81, 447. (b) For a comprehensive theoretical treatment of many of the processes proposed to occur in the Fischer-Tropsch synthesis, as well as many experimental references, see: Hoffmann, R.; Apeliog, Y.; Zheng, C. J. Am. Chem. Soc. 1988 110,749 . 
at the carbene carbon; for example, bases such as tertiary phosphines will add to the carbene carbon to form simple adducts with a typical Fischer-type carbene such as $(\mathrm{CO})_{5} \mathrm{~W}=\mathrm{C}(\mathrm{OH}) \mathrm{H}^{2}$ The complexes in the second group are called Schrock-type carbenes or alkylidene complexes. ${ }^{1,4}$ In the Schrock-type carbene complex $R$ and $\mathrm{R}^{\prime}$ are organic in nature ( $H$ or alkyl); the ligated carbon acts as a nucleophile toward other chemical reagents. Alkylidenes can carry out a Wittig-type transformation, eq 2 .

$$
\mathrm{L}_{n} \mathrm{M}=\mathrm{C}(\mathrm{R}) \mathrm{R}^{\prime}+>\mathrm{C}=\mathrm{O} \rightarrow \mathrm{L}_{n} \mathrm{M}=\mathrm{O}+>\mathrm{C}=\mathrm{C}(\mathrm{R}) \mathrm{R}^{\prime}
$$

The reactivity of carbenes in reactions such as olefin metathesis, eq 1 , and ring-opening metathesis polymerization has repeatedly been explained in light of the various bonding models that have been invoked to describe the metal-alkylidene bond. ${ }^{1-5,22-26}$ The Herrison-Chauvin mechanism for olefin metathesis involves the initial formation of an alkylidene/olefin complex as shown in step i of eq 1 , followed by a [ $2+2]$ cycloaddition, step ii in eq 1 , to yield four-membered-ring structures-metallacyclobutanes; these metallacyclobutanes then undergo a $[2+2]$ cycloreversion, step iii in eq 1 , to form an olefin and an alkylidene, eq $1 .{ }^{25}$ Gassman and Johnson have interpreted the formation of predominantly "degenerate metathesis" products (i.e., the $M-C$ and $C-C$ bonds of the metallacyclobutane cleave so as to yield back the original olefin and alkylidene complex) in the metathesis of terminal olefins as indicating that the chain-carrying species is a substituted metal-alkylidene rather than a nonsubstituted methylidene complex. ${ }^{30}$ The catalyst system used in their study was $\mathrm{PhWCl}_{3}$ / $\mathrm{AlCl}_{3}$. Since alkyl groups are better electron donors than hydrogen, it is argued, the greater stability of a substituted alkylidene versus a nonsubstituted methylidene complex is support for $\mathrm{M}^{-}-\mathrm{C}^{+}$ polarization in the metal-carbon bond. ${ }^{30}$ Complexes with this polarization of the $\mathrm{M}-\mathrm{C}$ bond are expected to act as electrophiles in chemistry centered at the trigonal carbon. Casey and coworkers, on the other hand, have interpreted their experimental data in terms of supporting a polarization in the opposite sense, i.e. $\mathrm{M}^{+}-\mathrm{C}^{-31}$ The ability of the $\mathrm{Nb}$ and $\mathrm{Ta}$ alkylidene complexes to carry out the Wittig reaction, eq 2, is also given as strong proof for $\mathrm{M}^{+}-\mathrm{C}^{-}$polarization. ${ }^{32}$ Electrophilic carbenes react with olefins to yield predominantly cyclopropanes. ${ }^{33}$ Ivin et al. have correlated the degree of head-to-tail bias in the ring-opening metathesis polymerization of asymmetric norbornenes as being intimately linked to the direction and degree of polarization in the $\mathrm{M}-\mathrm{C}$ bond. ${ }^{34}$

Theoretical investigations of multiply bonded carbon ligands have understandably focused on describing the nature of the bonding in the metal-carbon linkage. ${ }^{6-21}$ Various electronic structural arguments of both a qualitative and a quantitative nature have been forwarded to account for the differences in the reactivity of the Fischer-type and Schrock-type complexes. The various organometallic electron-counting schemes which have been proposed tend to view the metal-carbon linkage from one of two extremes. ${ }^{3}$ In the first case, the ligand is viewed as a four-electron donor, $\mathrm{CR}_{2}{ }^{2-}$, bound to the metal fragment, $\mathrm{L}_{n} \mathrm{M}^{q+2}$, in a largely ionic fashion. This bonding description is most frequently applied to the high-valent, Schrock-type alkylidene complexes and can be represented by the resonance structure $\mathrm{M}_{\leftarrow}^{\leftarrow} \mathrm{C}$. Thus, complexes such as $\mathrm{Cp}_{2} \mathrm{Ti}\left(\mathrm{CH}_{2}\right), \mathrm{R}_{3} \mathrm{Ta}\left(\mathrm{CHR}^{\prime}\right), \mathrm{CpCl}_{2} \mathrm{Nb}\left(\mathrm{CH}_{2}\right), \mathrm{Mo}(\mathrm{OR})_{2^{-}}$ (NAr) $\left(\mathrm{CHR}^{\prime}\right.$ ), etc. are most commonly viewed as having the metal in its highest formal oxidation state. At the other extreme, the ligand is depicted as a neutral substituent covalently bound to the transition-metal fragment. This description of the bonding is the one usually applied to Fischer-type carbenes ${ }^{3}$ and can be repre-

(30) Gassman, P.; Johnson, T. J. J. Am. Chem. Soc. 1977, 99, 622

(31) (a) Casey, C. P.; Polichowski, S. W. J. Am. Chem. Soc. 1977, 99,

6097. (b) Casey, C. P.; Tuinstra, H. J. J. Am. Chem. Soc. 1978, 100, 2270.

(32) Schrock, R. R. J. Am. Chem. Soc. 1976, 98, 5399

(33) (a) Brookhart, M.; Studabaker, W. B. Chem. Rev. 1987, 87, 411. (b) Brookhart, M.; Humphrey, M. B.; Kratzer, H. J.; Nelson, G. O. J. Am. Chem. Soc. 1980, 102, 7802.

(34) Ardill, H. E.; Greene, R. M. E.; Hamilton, J. G.; Ho, H. T.; Ivin, K. J.; Lapienis, G.; McCann, G. M.; Rooney, J. J. In Ring Opening Polymerization; McGrath, J. E., Ed.; American Chemical Society: Washington, 1985; p 285.
Chart I. Schematic Representation of Single (1a) and Triplet (1b) Carbene Bonding to a Transition-Metal Fragment

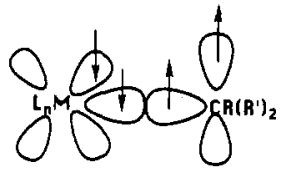

$1 \mathrm{a}$

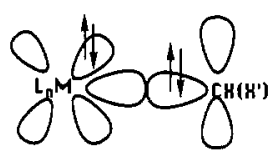

$1 \mathrm{~b}$ sented schematically by the Lewis structure, $\mathrm{M}=\mathrm{C}$. Thus, the complexes $\mathrm{Mo}(\mathrm{CO})_{5}(=\mathrm{CH}(\mathrm{OH})), \mathrm{W}(\mathrm{CO})_{5}\left(=\mathrm{CPh}_{2}\right)$, and $\mathrm{FeCp}$ (1,2-bis(diphenylphosphino)ethane) $\left(=\mathrm{CH}_{2}\right)^{+}$can all be considered to be low-spin, $\mathrm{d}^{6}$ pseudooctahedral complexes. The Fe complex is particularly interesting since it possesses $H$ substituents on the carbene carbon, but its reactivity (it is used in organic synthesis as a cyclopropanating reagent) is characteristic of the Fischer-type carbenes, perhaps due to the positive charge. ${ }^{33}$

Hall and Taylor ${ }^{7}$ have used ab initio calculations with limited electron correlation to delineate the differences between the electronic structures of the Fischer- and Schrock-type carbenes. On the basis of the results of their calculations, the Fischer-type and Schrock-type carbenes are viewed as arising from the coordination of a neutral carbene to the metal fragment in one of two ways. Schrock-type alkylidenes are constructed by the singlet coupling of a neutral, triplet (ground state) carbene ligand with a triplet transition-metal moiety $\left(C R\left(R^{\prime}\right)\right.$ in $\left.1 a\right)$; nearly covalent $\mathrm{M}-\mathrm{C} \sigma$ and $\pi$ bonds are formed. This bonding scheme most closely resembles the $\mathrm{M}=\mathrm{C}$ resonance structure. Fischer-type carbenes are formed by the coordination of a neutral, singlet (ground state) carbene $\left(\mathrm{CX}\left(\mathrm{X}^{\prime}\right)\right.$ in $\mathbf{1 b} ; \mathrm{X}, \mathrm{X}^{\prime}$ are electronegative ligands); a dative carbon-to-metal $\sigma$ bond with a dative metalto-carbon $\pi$ back-bond is formed. ${ }^{7}$ A resonance structure such as $\mathrm{M} \rightarrow \mathrm{C}$ (the metal-carbon $\sigma$ bond is described by the bottom arrow, the metal-carbon $\pi$ bond is described by the top arrow) can be used to portray the singlet-carbene coordination model. It does not seem likely that the bonding in such a complicated system can be described by only one resonance structure or electron configuration. Rather the bonding is expected to be a linear combination of two or more configurations.

The purpose of the present research is to study the bonding of prototypical alkylidenes at a relatively high level of electronic structure theory and to devise and implement a theoretical formalism which will allow us to more accurately quantify the importance of the resonance structures which contribute to the description of the bonding in transition-metal alkylidenes. This paper is organized in the following fashion. First, the outcome of geometry optimization at different levels of theory is reported and compared to available experimental information. Second, the theoretical scheme used to determine the primary resonance contributors is applied to the model complexes. In the present paper only methylidene complexes will be studied; future papers will deal with the effect of ligand substitution, carbene substitution, and changing the metal on the nature of the metal-alkylidene bond. The complexes of present interest are high-valent, pseudotetrahedral alkylidene complexes of the type $\mathrm{M}(\mathrm{X})(\mathrm{Y})(\mathrm{Z})=$ $\mathrm{CH}_{2}\{\mathrm{M}=\mathrm{Ta}, \mathrm{Nb}$ and $\mathrm{X}=\mathrm{Y}=\mathrm{Z}=\mathrm{H} ; \mathrm{M}=\mathrm{Mo}$, $\mathrm{W}$ and $\mathrm{X}$ $=\mathrm{Y}=\mathrm{OH}$ and $\mathrm{Z}=\mathrm{NH} ; \mathrm{M}=\operatorname{Re}$ and $\mathrm{X}=\mathrm{Y}=\mathrm{OH}$ and $\mathrm{Z}=$ $\mathrm{CH}$. The $\mathrm{Ta}$ and $\mathrm{Nb}$ complexes are models for the group VB alkylidene complexes, e.g. tantalum and niobium tris(neopentyl)neopentylidene. ${ }^{4,23,32,35}$ The $\mathrm{Mo}, \mathrm{W}$, and $\mathrm{Re}$ complexes are models for the high-valent, Lewis acid free olefin metathesis

(35) (a) Schrock, R. R, J. Am. Chem. Soc. 1974, 96, 6796. (b) Schrock, R. R. J. Am. Chem. Soc. 1975, 97, 6577. (c) Schrock, R. R. J. Am. Chem. Soc. 1975, 97, 6578. (d) Wood, C. D.; McLain, S. J.; Schrock, R. R. J. Am. Chem. Soc. 1977, 99, 3519. (e) Schrock, R. R.; Sharp, P. R. J. Am. Chem. Soc. 1978, 100, 2389. (f) Fellmann, J. D.; Schrock, R. R. J. Am. Chem. Soc. 1978, 100, 3359. (g) Wood, C. D.; McLain, S. J.; Schrock, R. R. J. Am. Chem. Soc. 1979, 101, 3210. (h) Schrock, R. R.; Fellmann, J. D.; Ruprecht, G. A. J. Am. Chem. Soc. 1979, 101, 5099. (i) Schrock, R. R.; Fellmann, J. D.; Ruprecht, G. A. J. Am. Chem. Soc. 1981, 103, 5752. (j) Wallace, K. C.; Dewan, J. C.; Schrock, R. R. Organometallics 1986, 5, 2162. (k) Wallace, K. C.; Schrock, R. R. Macromolecules 1987, $20,448$. 
Chart II. Planar (2a) and Twisted (2b) Geometries for Group IVB Alkylidenes

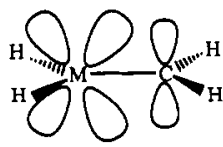

$2 a$

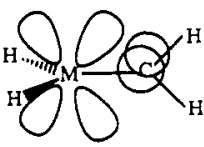

$2 b$ catalysts that have been recently developed by Schrock and coworkers. ${ }^{23.36}$ When the standard organometallic electron-counting conventions are employed (i.e. the ligands are $\mathrm{H}^{-}, \mathrm{OH}^{-}, \mathrm{CH}_{2}{ }^{2-}$, $\mathrm{NH}^{2-}$, and $\left.\mathrm{CH}^{3-}\right),{ }^{3}$ the transition metal in all of the compounds studied here is in its highest available formal oxidation state; i.e. the metal is $d^{0}$. Group IVB $\left(\mathrm{H}_{2} \mathrm{M}=\mathrm{CH}_{2}, \mathrm{M}=\mathrm{Ti}, \mathrm{Zr}, \mathrm{Hf}\right)$ alkylidenes have also been included for comparison with previous theoretical work ${ }^{11,12,19,20}$ and have been proposed as the active species in the catalysis of reactions such as olefin metathesis and polymerization and Wittig-type transformations and other reactions of synthetic interest. ${ }^{3,37,38}$

\section{Calculations}

The calculations described herein were carried out at the ab initio level with the GAMESS quantum chemistry program package. ${ }^{39}$ To reduce the computational demand involved in ab initio treatments of heavy elements, effective core potentials (ECPs) are employed in the present work. ${ }^{40-44}$ The use of ECPs to replace the core electrons greatly increases the speed at which transition-metal calculations can be carried out. Partitioning the orbitals of main group elements into core and valence groups is relatively straightforward; however, this is less clear for transition metals. Schemes have been derived in which those AOs that are typically considered subvalent, i.e., the $n$ s and the $n$ p, have ${ }^{43}$ and have not ${ }^{44}$ been

(36) W alkylidene complexes: (a) Schrock, R. R.; Depue, R. T.; Feldman, J.; Yap, K. B.; Yang, D. C.; Davis, W. M.; Park, L.; DiMare, M.; Schofield, M.: Anhaus, J.: Walborsky, E.; Evitt, E.: Krüger, C.: Betz, P. Organometallics 1990, 9, 2262. (b) Schrock, R. R.; DePue, R. T.; Fellmann, J. D.; Schaverian, C. J.; Dewan, J. C.; Liu, A. H. J. Am. Chem. Soc. 1988, 110,1423 . (c) Schaverian, C. J.; Dewan, J. C.; Schrock, R. R. J. Am. Chem. Soc. 1986, 108 2771. (d) Wengrovius, J. H.: Schrock, R. R. Churchill, M. R.: Missert, J. R.; Youngs, W. J. J. Am. Chem. Soc. 1980, 102, 4515. (e) Knoll, K.; Schrock, R. R. J. Am. Chem. Soc. 1989, 111 , 7989. (f) Schlund, R.; Schrock, R. R. Crowe, W. E. J. Am. Chem. Soc, 1989, 111,8004 . (8) Feldman, J. Davis, W. M.; Schrock, R. R. Organometallics 1989, 8, 2266. (h) Schrock, R. R. Feldman, J.; Cannizzo, L. F.; Grubbs, R. H. Macromolecules 1987, 20, 1169 (i) DePue, R. T.; Feldman, J.; Schaverian, C. J.; Dewan, J. C.; Liu, A. H. J. Am. Chem. Soc. 1988, 110, 1423. (j) Johnson, L. K.; Virgil, S. C.; Grubbs, R. H.; Ziller, J. W. J. Am. Chem. Soc. 1990, 112, 5384 . Mo alkylidene complexes: (k) Murdzek, J. S.; Schrock, R. R. Organometallics 1987, 6, 1373 (1) Schrock, R. R.; Murdzek, J. S.; Bazan, G. S.; Robbins, J.; DiMare, M. O'Regan, M. J. Am. Chem. Soc. 1990, 112, 3875. Re alkylidene complexes: (m) Schrock, R. R.; Toreki, R. J. Am. Chem. Soc. 1990, 112,2448 . (n) Horton, A. D.; Schrock, R. R. Polyhedron 1988, 7, 1841. (o) Horton, A. D. Schrock, R. R.; Freudenberger, J. H. Organometallics 1987, 6, 893. (p) Edwards, D. S.; Biondi, L. V.; Ziller, J. W. Churchill, M. R.; Schrock, R. R. Organometallics 1983, 2, 1505 . (q) Schrock, R. R.; Weinstock, I. A.; Horton, A. D.; Liu, A. H.; Schofield, M. H. J. Am. Chem. Soc. 1988, 110 2686. Mo and W alkylidene complexes: (r) Knoll, K.: Krause, S. A. Schrock R. R. J. Am. Chem. Soc. 1988, 110, 4424. (s) Feldman, J.; Murdzek, J. S. Davis, W. M.; Schrock, R. R. Organometallics 1989, 9, 2260. (t) Murdzek, J. S.; Schrock, R. R. Macromolecules 1987, 20, 2640.

(37) (a) Schwartz, J.: Clift, S. M. J. Am. Chem. Soc. 1984, 106, 8300. (b) Schwartz, J.; Hartner, F. W.; Clift, S. M. J. Am. Chem. Soc. 1983, 105, 640

(38) (a) Grubbs, R. H.; Mackenzie, P. B.; Ott, K. C. Pure Appl. Chem 1984, 56, 59. (b) Brown-Wensley, K. A.; Buchwald, S. L.; Cannizzo, L. Clawson, L. Ho S. Meinhart, D. Stille, J.R. Straus, D. Grubbs, R H. Pure Appl. Chem. 1983, 55, 1733. (c) Lee, G. J.; Gajda, G. J.; Schaefer, W. P. Howard, T. R.; Ikariya, T.; Straus, D. A.; Grubbs, R. H. J. Am. Chem. Soc. 1981, 103. 7358. (d) Gilliom. L. R.: Grubbs. R. H. J. Am. Chem. Soc. 1986 108, 733. (e) Gilliom, L R : Grubbs, R H Organometallics $1986,5,721$

(39) GAMESs (General Atomic and Molecular Electronic Structure System): Schmidt, M. W.; Baldridge, K. K.; Boatz, J. A.; Jensen, J. H.; Koseki S.; Gordon, M. S.; Nguyen, K. A.; Windus, T. L.; Elbert, S. T. QCPE Bull. $1990,10,52$.

(40) The problems inherent to the application of quantum chemical techniques to transition-metal species and the approaches taken to solve them are discussed in refs 40 and 41 . Zerner, M. C.; Salahub, D. The Challenge of d-and f-Electrons; American Chemical Society: Washington, 1989.

(41) Quantum Chemistry: The Challenge of Transition Metals and Coordination Chemistry; Veillard, A., Ed.; Reidel: Dordrecht, 1986.

(42) Szasz, L. Pseudopotentials; Wiley: New York, 1985.

(43) Hay, P. J.: Wadt, W. R. J. Chem. Phys, 1985, 82, 270

(44) Krauss, M.; Stevens, W. J.; Jasien, P. G.; Basch, H. Unpublished results.
Table I. $\mathrm{HF} \mathrm{H}_{2} \mathrm{M}=\mathrm{CH}_{2}$ Geometries ${ }^{a, b}$<smiles>[1H][14CH2][1H]</smiles>

planar/singlet minima

\begin{tabular}{llll}
\hline & \multicolumn{1}{c}{$\mathrm{Ti}$} & \multicolumn{1}{c}{$\mathrm{Zr}$} & $\mathrm{Hf}$ \\
\hline $\mathrm{M}-\mathrm{C}$ & $1.96(1.87)$ & $1.99(1.99)$ & $2.23(1.98)$ \\
$\mathrm{M}-\mathrm{H}$ & $1.78(1.78)$ & $1.94(1.94)$ & $2.02(1.92)$ \\
$\mathrm{H}-\mathrm{M}-\mathrm{H}$ & $126(126)$ & $122(124)$ & $121(125)$ \\
$\mathrm{H}-\mathrm{C}-\mathrm{H}$ & $109(111)$ & $109(111)$ & $111(111)$ \\
energy & -43.1175 & -42.6141 & -42.5121 \\
& $(-97.3142)$ & $(-86.2875)$ & $(-88.2028)$ \\
$\mathrm{ZPE}$ & $20.7(21.0)$ & $21.2(20.9)$ & $21.6(21.3)$
\end{tabular}

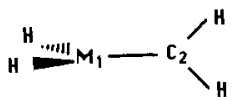

twisted/singlet second-order saddle point

\begin{tabular}{llll}
\hline & \multicolumn{1}{c}{$\mathrm{Ti}$} & \multicolumn{1}{c}{$\mathrm{Zr}$} & \multicolumn{1}{c}{$\mathrm{Hf}^{\mathrm{c}}$} \\
\hline $\mathrm{M}-\mathrm{C}$ & $1.78(1.85)$ & $1.95(1.96)$ & $2.21(1.97)$ \\
$\mathrm{M}-\mathrm{H}$ & $1.80(1.78)$ & $1.98(1.98)$ & $2.04(1.93)$ \\
$\mathrm{H}-\mathrm{M}-\mathrm{H}$ & $143(134)$ & $134(133)$ & $131(130)$ \\
$\mathrm{H}-\mathrm{C}-\mathrm{H}$ & $114(112)$ & $112(112)$ & $111(111)$ \\
energy & -43.0887 & -42.5766 & -42.4780 \\
& $(-97.2947)$ & $(-86.2597)$ & $(-88.1775)$ \\
$\mathrm{ZPE}$ & $18.8(19.5)$ & $18.8(19.2)$ & $20.1(19.6)$ \\
$\nu_{1}^{d}$ & $480 \mathrm{i}(519 \mathrm{i})$ & $698 \mathrm{i}(581 \mathrm{i})$ & $873 \mathrm{i}(574 \mathrm{i})$ \\
$\nu_{2}^{e}$ & $295 \mathrm{i}(178 \mathrm{i})$ & $335 \mathrm{i}(343 \mathrm{i})$ & $245 \mathrm{i}(325 \mathrm{i})$
\end{tabular}

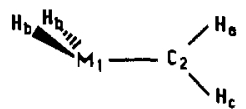

bent, twisted transition state

\begin{tabular}{llll}
\hline & \multicolumn{1}{c}{$\mathrm{Ti}$} & \multicolumn{1}{c}{$\mathrm{Zr}^{f}$} & $\mathrm{Hf}$ \\
\hline $\mathrm{M}-\mathrm{C}$ & $1.79(1.84)$ & $1.93(1.96)$ & $2.21(1.96)$ \\
$\mathrm{M}-\mathrm{H}$ & $1.77(1.77)$ & $1.93(1.91)$ & $2.01(1.89)$ \\
$\mathrm{H}_{\mathrm{b}}-\mathrm{M}-\mathrm{C}$ & $102(110)$ & $105(106)$ & $110(108)$ \\
$\mathrm{M}-\mathrm{C}-\mathrm{H}_{\mathrm{b}}$ & $116(110)$ & $91(99)$ & $118(108)$ \\
$\mathrm{M}-\mathrm{C}-\mathrm{H}_{\mathrm{b}}$ & $133(138)$ & $157(149)$ & $131(141)$ \\
energy & -43.0943 & -42.5861 & -42.4806 \\
& $(-97.2957)$ & $(-86.2675)$ & $(-88.1830)$ \\
$\nu_{3}^{e}$ & $539 \mathrm{i}(431 \mathrm{i})$ & $457 \mathrm{i}(402 \mathrm{i})$ & $675 \mathrm{i}(400 \mathrm{i})$ \\
$\mathrm{ZPE}$ & $19.6(20.2)$ & $20.3(19.8)$ & $20.1(20.4)$ \\
\hline
\end{tabular}

a Basis A, basis B (in parentheses). See text for a detailed description of basis sets. The addition of a diffuse function (for the carbene C) to Basis B did not change the geometry of the stationary points significantly $\left(\Delta r \leq 0.01 \AA, \Delta \theta \leq 1^{\circ}\right)$. ${ }^{b}$ Bond distances in $\AA$; bond angles in deg; energy in hartrees; ZPE (zero-point energy) in kcal $\mathrm{mol}^{-1} ; \nu(\mathrm{M}-\mathrm{C})$ in $\mathrm{cm}^{-1}$. The $\mathrm{C}-\mathrm{H}$ distance in all species shown was 1.09 . $0.01 \AA$ upon geometry optimization unless otherwise noted. ' For basis $\mathrm{A}, \mathrm{H}_{2} \mathrm{HfCH}_{2}$ has a third imaginary frequency (822i) corresponding to $\mathrm{MH}_{2}$ in-plane bending or rocking. Following this mode and reoptimizing leads to a structure with two imaginary frequencies (354i and 185i) which are analogous to the two imaginary frequencies in the other second-order saddle points; the energy of this structure is -42.4806 hartrees with a ZPE of $19.8 \mathrm{kcal} \mathrm{mol}^{-1}$. The geometry is as follows: $\mathrm{Hf}-\mathrm{C}=2.30 \AA ; \mathrm{Hf}-\mathrm{H}_{\mathrm{b}}=2.02 \AA ; \mathrm{Hf}-\mathrm{H}_{\mathrm{c}}=2.04 \AA$ $\mathrm{H}_{b}-\mathrm{HF}-\mathrm{C}=100^{\circ} ; \mathrm{H}_{\mathrm{c}}-\mathrm{Hf}-\mathrm{C}=129^{\circ} ; \mathrm{H}-\mathrm{C}-\mathrm{H}=111^{\circ}$.

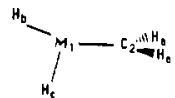

This mode corresponds predominantly to rotation about the $\mathrm{M}-\mathrm{C}$ bond. 'This mode corresponds to an out-of-plane bending or wagging of the $\mathrm{MH}_{2}$ fragment. $f$ For this compound $\mathrm{C}-\mathrm{H}_{2}=1.11 \AA(1.11 \AA)$ and $\mathrm{C}-\mathrm{H}_{\mathrm{c}}=1.07 \AA(1.08 \AA)$.

replaced by ECPs. The advantage of the latter is greater accuracy for some calculated properties at the expense of increased computational time. In the present research ECPs are used for all transition-metal atoms; other atoms are calculated at the all-electron level.

The calculations were performed at the Hartree-Fock level with either the Hay-Wadt ${ }^{43}$ (hereafter denoted as HW) or the Stevens-BaschKrauss (SBK) ${ }^{44}$ pseudopotentials with a valence basis for the transition metals. The $\mathrm{C}$ and $\mathrm{H}$ atoms were calculated at the all-electron level 
employing either the 3-21G basis (with $\mathrm{HW}$ : referred to as basis $\mathrm{A}$ ) or 3-21G(d) (with SBK: referred to as basis B). The d-orbital polarization function for the carbon in the 3-21G(d) basis set has an exponent of 0.8.45 Since the nucleophilic behavior of the Schrock-type alkylidene complexes is suggestive of carbanionic nature on the ligated $\mathrm{C}$, some calculations were run in which a set of diffuse functions $\left(\xi_{1}=\xi_{p}=0.0438\right)$ was added to basis $B .{ }^{46}$ This basis set will be referred to as basis B+. The SBK scheme includes the $n$ s and $n p$ AOs along with the standard valence orbitals; i.e., $n d,(n+1) s$, and $(n+1)$ p. The HW scheme employed here treats only the latter three sets of orbitals and replaces the remaining core AOs with a pseudopotential.47

Stationary points on the potential energy surface (i.e., points for which the gradient or first derivative of the total energy with respect to nuclear coordinates is equal to zero) are obtained by using the method of Baker. ${ }^{49}$ The hessian (second derivative of the total energy with respect to nuclear coordinates) is calculated at each stationary point in order to characterize the point as a minimum (all positive force constants or, equivalently, no imaginary vibrational frequencies), transition state (one negative force constant and therefore one imaginary vibrational frequency), etc. The technique used to obtain localization of MOs is that described by Boys. ${ }^{50}$

\section{Results}

1. Structural Characterization of Model Alkylidene Complexes. a. Group IVB Alkylidenes. The geometry optimization results for the group IVB $\mathrm{H}_{2} \mathrm{M}=\mathrm{CH}_{2}$ species are summarized in Table I. The geometries for the group IVB models were either planar, $\mathbf{2 a}$, or twisted, $\mathbf{2 b}$. Only singlet states were investigated since the transition metal is formally $\mathrm{d}^{0}$ in this and all other complexes studied here. ${ }^{\text {s1 }}$

The interest in organometallic complexes of the group IVB metals has been spurred on by their use as catalysts in a wide

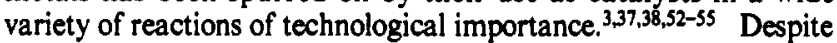

(45) The use of $3 \mathrm{~d}$ functions on the carbon atom does not imply that the high-energy 3d AOs of carbon are necessary to describe the bonding of carbon. The $d$ functions allow for movement of the center of the electronic charge away from the nuclei.

(46) For anions and atoms with substantial negative charge, diffuse functions (i.e. functions with small Gaussian exponents and hence larger size) are added to the basis to improve the description of the bonding. The extra electrons which characterize anionic species tend to be less tightly bound, and thus bigger in size, due to increased nuclear shielding so that basis functions which are also larger in size are needed to describe them. For further discussion on the use of polarization and diffuse functions in $\mathrm{ab}$ initio calculations and the results obtained with the various basis sets consult: Hehre, W. J.; Radom, L.; Schleyer, P. v. R.; Pople, J. A. Ab-Initio Molecular Orbital Theory; Wiley: New York, 1986; Section 4.3.

(47) Hay and Wadt (ref 48) have developed pseudopotentials and valence basis sets which include the ns and np along with the typical valence AOs; these were not used here.

(48) Hay, P. J.; Wadt, W. R. J. Chem. Phys. 1985, 82, 299.

(49) Baker, J. J. Comp. Chem. 1986, 7, 385.

(50) Foster, J. M.; Boys, S. F. Rev. Mod. Phys, 1960, 32, 300

(51) The presence of low-energy triplet states must not be so quickly dismissed, particularly for the coordinatively unsaturated systems under present study as well as the twisted $\mathrm{H}_{2} \mathrm{MCH}_{2}$ complexes. It is well-known that twisting one of the methylene groups of ethylene by $90^{\circ}$ about the $\mathrm{C}-\mathrm{C}$ axis will lead to low-energy triplet (biradical) and singlet (zwitterionic) states. These zwitterionic states should ideally be described with multideterminant wave functions. When triplet states (ROHF) were optimized for $\mathrm{H}_{2} \mathrm{MCH}_{2}$ $(\mathbf{M}=\mathrm{Ti}, \mathrm{Zr}, \mathrm{Hf}$; twisted and planar) all stationary points were found to be similar in geometry to their singlet counterparts other than a lengthening of the $\mathrm{M}-\mathrm{C}$ bond $(\approx 0.1-0.2 \mathrm{~A})$. The twisted triplets are transition states (the imaginary mode corresponds to rotation about the $\mathrm{M}-\mathrm{C}$ bond); the planar triplets are second-order saddle points. UHF calculations on the twisted singlet led to highly spin contaminated wave functions. Also, motions that cause the $\mathrm{CH}_{2}$ group to deviate from planarity should ideally be considered. However, to our knowledge, no carbene complex has been characterized which deviates significantly from planar coordination about the carbene carbon. For an analysis of these motions in main-group ethylene analogues see: Schmidt, M. W.; Gordon, M. S.; Dupuis, M. J. Am. Chem. Soc. 1985, 107, 2585 Schmidt, M. W.; Truong, P. N.; Gordon, M. S. J. Chem. Soc. 1987, 109. 5217

(52) Parshall, G. W. Homogeneous Catalysis; Wiley: New York, 1980. (53) Katakis, D.; Gordon, G. Mechanisms of Inorganic Reactions; Wiley: New York, 1987.

(54) (a) Tebbe, F. N.; Parshall, G. W.; Reddy, G. S. J. Am. Chem. Sac 1978, 100,3611 . (b) Tebbe, F. N. Parshall, G. W. Ovenall, D. W. J Am. Chem. Soc. 1989, 101, 5074. (c) Pine, S. H.; Zahler, R.; Evans, D. A.; Grubbs, R. H. J. Am. Chem. Soc. 1980, 102, 3270.

(55) (a) Binger, P.; Muller, P.; Benn, R.; Mynott, R. Angew. Chem., Int. Ed. Engl. 1989, 28, 610. (b) Titanocene-vinylidene complexes, which can be considered to be analogues of allene, have been postulated as intermediates in the synthesis of bicyclic titanium-cyclobutanes and -cyclobutenes. Dennehy, R. D.; Whitby, R. J. J. Chem. Soc., Chem. Commun. 1990, 1060
Chart III. Staggered (3a), Eclipsed (3b), and "Hyperconjugated" (3c) Conformers for Group VB

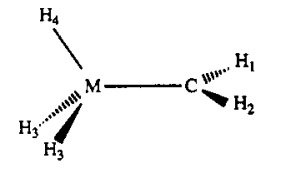

$3 a$

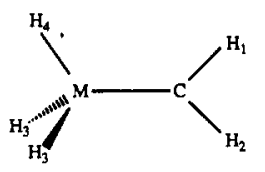

$3 b$

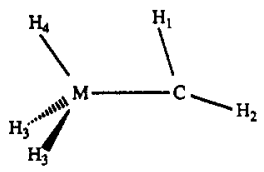

$3 c$ their being the proposed intermediates in a wide range of important reactions, no group IVB alkylidenes have been structurally characterized by X-ray or neutron-diffraction techniques. Calculated $\mathrm{Ti}=\mathrm{C}$ bond lengths fall in the range $1.88^{12 \mathrm{c}}$ to $1.96 \AA .^{11}$ Goddard and Rappe obtained an equilibrium bond length of 1.89 $\AA$ for a $\mathrm{Cl}_{2} \mathrm{Ti}=\mathrm{CH}_{2}$ model complex using a double- $\zeta$ quality basis set to generate generalized valence bond (GVB) wave functions in which the $\mathrm{Ti}-\mathrm{C} \sigma$ and $\pi$ bonds were correlated. ${ }^{19 d}$ This value is in good agreement with the $1.87 \AA$ calculated by basis B. On the other hand, the Ti-C bond length predicted by basis $\mathrm{A}$ is 0.09 $\AA$ longer, possibly due to the lack of d-polarization functions in the carbon basis.

The twisted group IVB carbenes (2b) have two imaginary frequencies-one which corresponds largely to rotation about the $\mathrm{M}-\mathrm{C}$ bond leading to the planar structure (2a) and one which entails bending of the $\mathrm{MH}_{2}$ fragment such that the coordination about the metal goes from trigonal planar to pyramidal. This pyramidalization of the transition metal is interesting in connection with the observation that it is the "metal" in twisted silaethylene $\left(\mathrm{H}_{2} \mathrm{SiCH}_{2}\right)$ which is pyramidalized. ${ }^{51}$ The structures with a pyramidalized coordination about the metal are transition states; the imaginary frequencies correspond to rotation about the $\mathrm{M}-\mathrm{C}$ bond as well as a "flattening out" of the $\mathrm{MH}_{2}$ fragment leading to the planar minimum. Note that the pyramidalization has a significant effect on the internal rotation frequency (Table I).

A qualitative estimate of the $\mathrm{Ti}=\mathrm{C}$ bond length may be obtained as follows. The equilibrium bond length in TiO ( ${ }^{3} \Delta$ ground state) is $1.62 \AA .{ }^{56}$ Given an $\mathrm{O}=\mathrm{O}$ bond length of $1.21 \AA$ in $\mathrm{O}_{2}$ $\left({ }^{3} \Sigma_{\mathrm{g}}^{-}\right)^{56 \mathrm{a}}$ and the empirical relationship ${ }^{57}$

$$
r_{\mathrm{ab}}=r_{\mathrm{a}}+r_{\mathrm{b}}-0.07\left(\chi_{\mathrm{a}}-\chi_{\mathrm{b}}\right)^{2}
$$

one can estimate (using Pauling electronegativities of 1.54 for $\mathrm{Ti}$ and 3.44 for $\mathrm{O}$ ) a double bonded covalent radius for $\mathrm{Ti}$ of 1.26 $\AA ;{ }^{58}$ the double bond covalent radius of $C$ is $0.66 \AA$. Using eq $3\left(\chi_{c}=2.55\right)$ yields a $\mathrm{Ti}=\mathrm{C}$ bond length of $1.85 \AA$, in good agreement with the more accurate calculated values. This agreement supports the notion that this bond is essentially covalent in nature. The addition of diffuse functions to the carbon, basis $\mathrm{B}+$, does not appreciably change the geometry at the stationary points. One can also estimate the $\mathrm{M}=\mathrm{C}$ bond lengths by consideration of the experimentally determined ${ }^{56 a}$ bond lengths for the ${ }^{1} \Sigma^{+}$state of the diatomic metal oxides $(\mathrm{Ti}=0=1.60 \AA$, $\left.\mathrm{Zr}=\mathrm{O}=1.71 \AA, \mathrm{Hf}=\mathrm{O}=1.72 \AA^{59}\right)$ and the changes which will arise from both the larger covalent radius of $C$ versus $O(C>$ $O$ by $0.04 \AA^{57 a}$ ) and the greater differential shortening in $r_{\mathrm{e}}$ for the more electronegative oxo ligand. In the second term, righthand side of eq $3, \delta=0.07\left(x_{M}-\chi_{0}\right)^{2}-0.07\left(x_{M}-\chi_{C}\right)^{2} \approx 0.13(3$ $\left.-\chi_{M}\right)(0.19 \AA$ for $\mathrm{Ti}$ and $0.22 \AA$ for $\mathrm{Zr}$ and $\mathrm{Hf})$. Thus, estimated $\mathrm{Ti}=\mathrm{C}, \mathrm{Zr}=\mathrm{C}$, and $\mathrm{Hf}=\mathrm{C}$ bond lengths $\left(\chi_{\mathrm{zr}}=1.33\right.$ and $\chi_{\mathrm{Hf}}=$

(56) (a) Huber, K. B.; Herzberg, G. Molecular Spectra and Molecular Structure; Van Nostrand: New York, 1979; Part IV. (b) A titanyl complex with a Ti-O bond length of $1.62 \AA$ has been structurally characterized. Hoim. R. H. Chem. Rev. 1987, 87, 1401 .

(57) (a) Porterfield, W. W. Inorganic Chemistry; Addison-Wesley: New York, 1984; p 167. It should be noted that eq 3 technically applies only to single bonds. (b) Similar empirical relationships have been derived by Schomaker and Stevenson, see: Pauling, L. The Nature of the Chemical Bond, 3rd ed.; Cornell: Ithaca, 1980; p 228.

(58) We have, of course, assumed for the present that the leading resonance contributor to the ground-state wave function of the titanium carbene complex is that with a formal double bond between the metal and the carbon.

(59) The ' $\Sigma^{+}$is the ground state for the ZrO and HrO species and $\approx 5600$ $\mathrm{cm}^{-1}$ above the ground state for $\mathrm{TiO}$, see ref $56 \mathrm{a}$. 
1.30) are expected to be longer than those of oxo derivatives by $0.23,0.26$, and $0.26 \AA$, respectively. This gives $\mathrm{T}=\mathrm{C}=1.83 \AA$, $\mathrm{Zr}=\mathrm{C}=1.97 \AA$, and $\mathrm{Hf}=\mathrm{C}=1.97 \AA$. These estimated $\mathrm{M}=\mathrm{C}$ bond lengths are in very good agreement with those values calculated with the bigger basis sets (B and $\mathrm{B}+$ ).

The basis $B$ barriers listed in Table I for rotation about the $M-C$ bonds $\left(11.6,12.5\right.$, and $12.4 \mathrm{kcal} \mathrm{mol}^{-1}$ for $\mathrm{M}=\mathrm{Ti}, \mathrm{Zr}$, and $\mathrm{Hf}$, respectively) are relatively small when compared to main group analogues such as ethylene (rotational barrier $\approx 65 \mathrm{kcal} \mathrm{mol}^{-1}$ ). The inclusion of zero-point energy and electron correlation corrections (Moller-Plesset second-order perturbation theory, $\mathbf{M P 2}^{61}$ ) to the planar minima and bent, twisted transition states reduce the calculated rotational barriers (using basis B) in the group IVB alkylidenes to $10.4,6.4$, and $7.9 \mathrm{kcal} \mathrm{mol}^{-1}$ for the $\mathrm{Ti}, \mathrm{Zr}$, and $\mathrm{Hf}$ alkylidenes, respectively. The rotational barrier for the methylidene ligand in $\left[\mathrm{Cp}_{2} \mathrm{Ti}\left(\mathrm{CH}_{2}\right) \mathrm{Me}\right]^{-}$is calculated to be $28 \mathrm{kcal}$ $\mathrm{mol}^{-1}$ with the extended Huickel theory. ${ }^{60}$ Employing the STO-3G basis Hehre et al. have calculated rotational barriers of $13 \mathrm{kcal}$ $\mathrm{mol}^{-1}$ for $\mathrm{H}_{2} \mathrm{TiCH}_{2}$ and $19 \mathrm{kcal} \mathrm{mol}^{-1}$ for $\mathrm{H}_{2} \mathrm{ZrCH}_{2}{ }^{12 \mathrm{c}}$ The rotational barriers calculated at the STO-3G level did not take pyramidalization of the $\mathrm{MH}_{2}$ fragment into consideration. ${ }^{12 \mathrm{c}}$ Rotational barriers for coordinatively saturated alkylidenes may be significantly higher. For example, the calculated rotational barrier in $\mathrm{Cp}_{2} \mathrm{TiCH}_{2}$ is $52 \mathrm{kcal} \mathrm{mol}^{-1}$ at the STO-3G level. ${ }^{12 \mathrm{c}}$ Note also the shortening of the metal-carbon distance that is observed upon rotating the methylene group by $90^{\circ} .12 \mathrm{~d}$ However, caution should be exercised in making comparisons with properties calculated at lower levels of theory.

There has been, to our knowledge, no reported vibrational data for group IV alkylidenes. Theoretically calculated vibrational frequencies do exist for $\mathrm{M}-\mathrm{H}$ bonds of Ti. ${ }^{62}$ The calculated (basis $B+)$ equilibrium stretching frequencies $\left(\omega_{e}\right)$ are 1651,1565 , and $1589 \mathrm{~cm}^{-1}$ for the $\mathrm{Ti}-\mathrm{H}, \mathrm{Zr}-\mathrm{H}$, and $\mathrm{Hf}-\mathrm{H}$ bonds, respectively. Bauschlicher has calculated $\omega_{\mathrm{e}}(\mathrm{Ti}-\mathrm{H})=1572 \mathrm{~cm}^{-1}$ for the ${ }^{4} \Phi$ ground state of $\mathrm{TiH}$ using a large basis set and full configuration interaction. ${ }^{62 \mathrm{a}}$

b. Group VB Alkylidenes. The results for the group VB alkylidene $(\mathbf{M}=\mathbf{N b}$ and $\mathrm{Ta})$ complexes are collected in Table II. The two basic geometries calculated were staggered (3a) and eclipsed (3b). Additional geometries were investigated; these additional geometries are those in which one of the $\mathrm{M}-\mathrm{C}-\mathrm{H}$ angles is acute but the $\mathrm{H}-\mathrm{C}-\mathrm{H}$ angle remains at approximately $115^{\circ}$ (3c). Hehre et al. have drawn an analogy between these distorted species and hyperconjugated organic analogues for the group IVB alkylidenes. ${ }^{12}$ The "hyperconjugated" geometries may also exist in staggered and eclipsed conformations. The coordination about the trigonal carbon in all stationary points found in the present work was classical. No "hyperconjugated" methylidene structures were found to be minima on the potential energy surfaces. The only $\mathrm{Ta}$ methylidene complex which has had its structure determined experimentally, bis(cyclopentadienyl)methylmethylenetantalum $\left(\mathrm{Cp}_{2} \mathrm{Ta}\left(\mathrm{CH}_{2}\right)\left(\mathrm{CH}_{3}\right)\right)$, possesses normal coordination about the carbene carbon. ${ }^{63}$ In contrast, Ta alkylidene complexes that have been characterized with alkyl substituents on the alkylidene carbon do show "hyperconjugation". 64

(60) Lauher, J. W.; Hoffmann, R. J. Am. Chem. Soc. 1976, 98, 1729 (61) (a) Moller, C.; Plesset, M. S. Phys. Rev. 1934, 46, 618. (b) Carsky, P.; Hess, B. A.; Schaad, L. J. J. Comput. Chem. 1984, 5, 280

(62) (a) Bauschlicher, C. W. J. Phys. Chem. 1988, 92, 3020. (b) Langhoff, S. R.; Pettersson, L. G. M.; Bauschlicher, C. W.; Partridge, H. J. Chem. Phys. 1987, 86, 268.

(63) (a) Schrock, R. R. J. Am. Chem. Soc, 1975, 97, 6577. (b) Schrock R. R.; Guggenberger, L. J. J. Am. Chem. Soc. 1975, 97, 6578. (c) The results of a neutron diffraction study of the undistorted Ta-methylidene are given in: Takusagawa, F.: Koetzle, T. F.: Sharp, P. R.; Schrock, R. R. Acto Crystallogr. 1988, C44, 439. (d) Schrock et al. report NMR evidence for a distorted methylidene in WCp*Me, $\left(\mathrm{CH}_{2}\right)$. Liu, A. H.; Murray, R. C.; Dewan, J. C.; Santarsiero, B. D.; Schrock, R. R. J. Am. Chem. Soc. 1987, 109, 4282. (64) Some structural data for Ta-alkylidene complexes are collected in Table 1 of ref 6a. Two Ta-neopentylidene complexes which have been characterized by neutron diffraction have $\mathrm{Ta}-\mathrm{C}-\mathrm{H}$ angles of $78^{\circ}(\mathrm{CP} * \mathrm{Ta}$. $\left.(-\mathrm{C}(\mathrm{H}) t-\mathrm{bu})\left(\mathrm{PMe}_{3}\right)\left(\mathrm{C}_{2} \mathrm{H}_{4}\right)\right)$ and $85^{\circ}\left(\left[\mathrm{Ta}(-\mathrm{C}(\mathrm{H}) t-\mathrm{bu}) \mathrm{Cl}_{3}\left(\mathrm{PMe}_{3}\right)\right]_{2}\right)$. The $\mathrm{C}_{f}-\mathrm{C}_{\mathrm{a}}-\mathrm{H}$ angles are $112^{\circ}$ and $114^{\circ}$, respectively. The $\mathrm{Ta}_{a}-\mathrm{C}_{\alpha}-\mathrm{C}_{\beta}$ angles are $170^{\circ}$ and $161^{\circ}$ for these same two complexes. For $\mathrm{Cp}_{2} \mathrm{Ta}\left(\mathrm{CH}_{2}\right)(\mathrm{Me})$ the $\mathrm{Ta}-\mathrm{C}_{\alpha}-\mathrm{H}$ angle is $126.5^{\circ}$ and the $\mathrm{H}-\mathrm{C}_{\alpha}-\mathrm{H}$ angle is $107^{\circ}$.
Table II. HF $\mathrm{H}_{3} \mathrm{M}=\mathrm{CH}_{2}$ Geometries $^{a}$

\begin{tabular}{|c|c|c|}
\hline & \multicolumn{2}{|c|}{ eclipsed } \\
\hline & $\mathrm{Nb}^{b}$ & $\mathrm{Ta}^{b}$ \\
\hline \multirow[t]{3}{*}{$\begin{array}{l}\mathrm{M}-\mathrm{C}^{c} \\
\mathrm{C}-\mathrm{H}_{1} \\
\mathrm{C}-\mathrm{H}_{2} \\
\mathrm{M}-\mathrm{H}_{3} \\
\mathrm{M}-\mathrm{H}_{4} \\
\mathrm{M}-\mathrm{C}-\mathrm{H}_{1} \\
\mathrm{M}-\mathrm{C}-\mathrm{H}_{2} \\
\mathrm{H}_{3}-\mathrm{M}-\mathrm{C}\left(\alpha_{1}\right) \\
\mathrm{H}_{4}-\mathrm{M}-\mathrm{C}\left(\alpha_{2}\right) \\
\text { energy } \\
\nu(\mathrm{M}-\mathrm{C})^{d} \\
\nu(\mathrm{M}-\mathrm{H}) \\
\mathrm{ZPE} \\
\alpha^{e} \\
\end{array}$} & $\begin{array}{l}1.88(1.90) \\
1.08(1.09) \\
1.09(1.09) \\
1.80(1.80) \\
1.80(1.81) \\
132(130) \\
115(115) \\
99(101) \\
117(113) \\
-45.2486(-96.6375) \\
683(843) \\
1720,1711(1755,1788) \\
25.6(25.9) \\
-12(-8)\end{array}$ & $\begin{array}{l}2.07(1.90) \\
1.08(1.09) \\
1.08(1.09) \\
1.88(1.80) \\
1.87(1.82) \\
127(131) \\
119(115) \\
101(102) \\
116(112) \\
-45.0517(-96.6072) \\
716(873) \\
1743,1744(1763,1809) \\
26.2(25.9) \\
-10(-7)\end{array}$ \\
\hline & & \\
\hline & 100 & $2 \pi$ \\
\hline $\begin{array}{l}\mathrm{M}-\mathrm{C}^{c} \\
\mathrm{C}-\mathrm{H}_{1} \\
\mathrm{C}-\mathrm{H}_{2} \\
\mathrm{M}-\mathrm{H}_{3} \\
\mathrm{M}-\mathrm{H}_{4} \\
\mathrm{M}-\mathrm{C}-\mathrm{H}_{1} \\
\mathrm{M}-\mathrm{C}-\mathrm{H}_{2} \\
\mathrm{H}_{3}-\mathrm{M}-\mathrm{C}\left(\alpha_{1}\right) \\
\mathrm{H}_{4}-\mathrm{M}-\mathrm{C}\left(\alpha_{2}\right) \\
\text { energy } \\
\nu(\mathrm{M}-\mathrm{C})^{\gamma} \\
\nu(\mathrm{M}-\mathrm{H}) \\
\mathrm{ZPE} \\
\alpha\end{array}$ & $\begin{array}{l}1.08(1.09) \\
1.08(1.09) \\
1.80(1.80) \\
1.79(1.79) \\
124(123) \\
124(123) \\
113(110) \\
90(95) \\
-45.2499(-96.6380) \\
676(839) \\
1714,1716(1755,1788) \\
26.1(26.1) \\
16(10)\end{array}$ & $\begin{array}{l}1.08(1.09) \\
1.08(1.09) \\
1.88(1.81) \\
1.88(1.81) \\
123(123) \\
123(123) \\
113(109) \\
93(98) \\
-45.0529(-96.6074) \\
713(868) \\
1748,1748(1815,1782) \\
26.6(26.5) \\
14(7)\end{array}$ \\
\hline
\end{tabular}

${ }^{a}$ Basis A, basis B (in parentheses). See text for a detailed description of basis sets. ${ }^{b}$ The optimized structure is a transition state on the $\mathrm{PES}$, i.e. one imaginary vibrational mode. For the eclipsed $\mathrm{Nb}$ complex the imaginary frequency is $271 \mathrm{i}$ and corresponds to rotation about the $\mathrm{Nb}-\mathrm{C}$ bond (toward a staggered conformation) and a change in the tilt angle $(\alpha)$, see footnote $d$, from negative to positive. The imaginary frequency for the Ta complex is at $256 \mathrm{i}$ and is similar in nature. 'Bond distances in $\AA$; bond angles in deg; energy in hartrees; ZPE in kcal $\mathrm{mol}^{-1} ; \nu(\mathrm{M}-\mathrm{C})$ in $\mathrm{cm}^{-1}$. ${ }^{d}$ Intrinsic stretching frequencies calculated with the normal coordinate analysis formalism described in: Boatz, $\mathbf{J}$. A.; Gordon, M. S. J. Phys. Chem. 1989, 93, 1819. 'The tilt angle $(\alpha)$, as defined by Wolfe et al., ${ }^{65 a}$ is the angle between the 3-fold axis of the $\mathrm{NbH}_{3}$ moiety and the vector described by the $\mathrm{Nb}-\mathrm{C}$ bond and is calculated with use of the equation $3 \cos \left(\alpha-\alpha_{1}\right)=4 \cos \left(\alpha_{2}\right)-\cos \left(\alpha_{1}\right)$. $f$ The optimized structure is a minimum on the PES and thus possesses no imaginary vibrational frequencies.

$\mathrm{Ta}$ and $\mathrm{Nb}$ alkylidene complexes are chemically similar to the phosphorus ylides, the simplest of which is methylenephosphorane $\left(\mathrm{H}_{3} \mathrm{P}=\mathrm{CH}_{2}\right)$. The nature of the chemical bond between the $\mathrm{P}$ and the $\mathrm{C}$ in phosphorus ylides has attracted considerable theoretical interest. ${ }^{65}$ The zwitterionic nature of the $\mathrm{P}=\mathrm{C}$ bond $\left(\mathrm{P}^{+}-\mathrm{C}^{-}\right)$has been used to explain the nucleophilic tendencies of the carbon in phosphorus ylides. $\mathrm{Ta}$ and $\mathrm{Nb}$ alkylidene complexes possess similar reactivity to the phosphorus ylides; for example, both compounds can carry out the olefination of carbonyls (the Wittig reaction, eq 2). ${ }^{66} \mathrm{Nb}$ and $\mathrm{Ta}$ alkylidene complexes have also been employed as olefin metathesis catalysts although they are prone to side reactions such as $\beta$-hydrogen migration and are not as long lived in solution as the more recently synthesized metathesis catalysts. ${ }^{67}$

(65) (a) Mitchell, D. J. Wolfe, S. Schlegel, H. B. Can. J. Chem. 1981 59. 3280. (b) Dixon, D. A.; Dunning, T. H.; Eades, R. A.; Gassman, P. G J. Am. Chem. Soc. 1983, 105, 7011. (c) Lischka, H. J. Am. Chem. Soc. 1977, 99. 353. (d) Yates, B. F.; Bouma, W.; Radom, L. J. Am. Chem. Soc. 1987, 109, 2250. (e) Dixon, D. A.; Smart, B. E. J. Am. Chem. Soc. 1986, $108,7122$. (f) Volatron, F.; Eisenstein, O. J. Am. Chem. Soc. 1984, 106, 6117. (g) Trinquier, G.; Malrieu, J. P. J. Am. Chem. Soc. 1979, 101, 7169.

(66) Johnson, A. W. Ylid Chemistry; Academic: New York, 1966.

(67) Powell, P. Principles of Organometallic Chemistry; Chapman and Hall: London; p 377 
The basis B and B+ equilibrium geometries for the group V alkylidene complexes are identical. The addition of diffuse functions to carbon yields stationary points whose bond lengths agree to the nearest $0.01 \AA$ and whose bond angles agree within a degree with those results obtained with basis $\mathrm{B}$. In the $\mathrm{Ta}$ alkylidene complex, as for the $\mathrm{Hf}$ alkylidene complex, there is a significant contraction of the metal-carbon bond upon switching from basis $A$ to those employing the SBK ECPs and valence basis set; other geometrical parameters were little changed. The eclipsed rotamers are transition states on the potential energy surfaces; the imaginary mode in each case corresponds to rotation about the $\mathrm{M}-\mathrm{C}$ bond and leads to the staggered conformation. The staggered conformations are minima.

Several test calculations were performed on $\mathrm{Hf}$ and $\mathrm{Ta}$ alkylidenes employing the SBK pseudopotentials and a 3-21G basis for $\mathrm{C}$ and $\mathrm{H}$ (i.e. basis $\mathrm{B}$ without a polarization function on the C). This is referred to as basis B-. The purpose of these calculations is to see if the difference in equilibrium geometries between basis $\mathrm{A}$ and basis $\mathrm{B}$ results from improving the basis set on the ligand. Those geometry optimizations which employed basis B- yield virtually identical equilibrium geometries to those obtained with basis $\mathrm{B}$ and $\mathrm{B}+$. This suggests that the changes in geometry for the third-row alkylidenes are due to improvement of the metal valence basis set and/or ECPs. The calculated $\mathrm{Ta}=\mathrm{C}$ bond length in the staggered conformation for the model 10electron complex $\mathrm{H}_{3} \mathrm{TaCH}_{2}$ (basis $\mathrm{B}$ and $\mathrm{B}+$ ) is $1.90 \AA$. This calculated bond length is $\approx 0.13 \AA$ shorter than that measured for 18-electron complexes such as $\left.\left.\mathrm{TaCp}_{2}\left(\mathrm{CH}_{3}\right) \mathrm{CH}_{2}\right)\right)^{4,63}$ However, the calculated $\mathrm{Ta}=\mathrm{C}$ bond length is in excellent agreement when compared to electron-deficient compounds such as the $1.90 \AA$ measured by neutron diffraction for the 14-electron ${ }^{68}$ complex $\left[\mathrm{TaCl}_{3}\left(\mathrm{PMe}_{3}\right)(=\mathrm{CHCMe})\right]_{2} \cdot{ }^{4}$ The calculated $\mathrm{Ta}-\mathrm{H}$ bond lengths (average of $1.81 \AA$ in basis $\mathrm{B}$ and $\mathrm{B}+$ ) are in good agreement with the average $\mathrm{Ta}-\mathrm{H}$ bond length of $1.78 \AA$ measured with use of neutron diffraction for the complex $\mathrm{Cp}_{2} \mathrm{TaH}_{3}{ }^{69}$ The average $\mathrm{Nb}-\mathrm{H}$ bond length of $1.69 \AA$ in $\mathrm{Cp}_{2} \mathrm{NbH}_{3}$, as measured by X-ray diffraction, ${ }^{69}$ is rather short compared with the calculated value of $1.81 \AA$ from basis B. Note, however, that the uncertainty in the X-ray value $( \pm 0.06 \AA)$ is much larger than that in neutron diffraction $( \pm 0.01 \AA)$ due to the instability of the $\mathrm{Nb}$ complex. ${ }^{69}$ Indeed, the $\mathrm{Nb}-\mathrm{H}$ bond lengths in $\mathrm{Cp}_{2} \mathrm{NbH}_{3}$ are expected to be very similar to those for the $\mathrm{Ta}$ analogue since $\mathrm{Nb}$ and $\mathrm{Ta}$ possess virtually identical covalent and ionic radii as well as comparable electronegativities. $57 \mathrm{a}$

As was the case for the group IV alkylidenes there is no vibrational data for $\mathrm{M}-\mathrm{C}$ bonds of group VB alkylidenes. The intrinsic $\omega_{\mathrm{e}}$ for the $\mathrm{Nb}-\mathrm{H}$ and $\mathrm{Ta}-\mathrm{H}$ bonds (basis $\mathrm{B}+$ ) are 1777 and $1793 \mathrm{~cm}^{-1}$, respectively. IR bands at $1710\left(\mathrm{Cp}_{2} \mathrm{Nb}(\mathrm{H})_{3}\right)$ and $1735 \mathrm{~cm}^{-1}\left(\mathrm{Cp}_{2} \mathrm{Ta}(\mathrm{H})_{3}\right)$ have been assigned to $\mathrm{M}-\mathrm{H}$ stretches. ${ }^{70}$ Related hydrido complexes of these metals also have IR bands in this region which have been assigned to $\nu_{\mathrm{MH}}$ modes. ${ }^{70}$

The bonding about the methylidene ligand is also different from that of its main group analogues, the phosphorus ylides, in that the carbene $\mathrm{C}$ possesses a planar coordination geometry in the former compounds. This deviation from ideal trigonal-planar geometry in phosphorus ylides has been ascribed to interaction of the $\mathrm{P}-\mathrm{H} \sigma$ bonds with the $\mathrm{C}$ lone pair. ${ }^{65 \mathrm{a}, 71}$ A calculation on $\mathrm{H}_{3} \mathrm{PCH}_{2}$ (using the HW ECPs for phosphorus, with a d exponent of 0.45 , and the $3-21 \mathrm{G}(\mathrm{d})$ basis for $\mathrm{C}, \mathrm{H}$ ) shows an admixture of $23 \% \mathrm{P}$ and $\mathrm{H}$ character in the HOMO which is concentrated largely on the carbon. In contrast, the $\mathrm{HOMO}$ in $\mathrm{H}_{3} \mathrm{Ta}=\mathrm{CH}_{2}$ (basis $\mathrm{B}+$, staggered geometry) is $46 \% \mathrm{Ta} \mathrm{d} \pi$ and $54 \% \mathrm{C}$ p $\pi$ with virtually no electron density on the hydrogens bound to tantalum $(<0.5 \%)$. A nearly zero rotational barrier about the $\mathrm{M}-\mathrm{C}$ bond is predicted for these compounds, as is the case for the phosphorus

(68) The various electronic counting schemes are discussed in ref $6 \mathrm{a}$. (69) Wilson, R. P.; Koetzle, T. F.; Hart, D. W.; Kvick, A.; Tipton, D. L.; Bau, R. J. Am. Chem. Soc. 1977, $99,1775$.

(70) Maslowsky, E. Vibrational Spectra of Organometallic Compounds; Wiley: New York, 1979; p 353.

(71) Albright, T. A.; Burdett, J. K.; Whangbo, M. H. Orbital Interactions in Chemistry; Wiley: New York, 1985; p 178.
Chart IV. $C$, Geometry of Models for Olefin Metathesis Catalysts

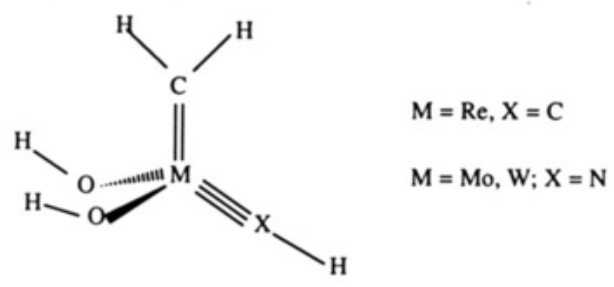

4

Chart V. Schematic Representation of Interaction between $\pi$ Orbitals on $\mathrm{C}$ and $\mathrm{N}$ with Metal $\mathrm{d} \pi \mathrm{AOs}$

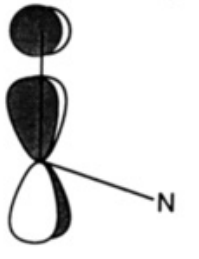

$5 a$

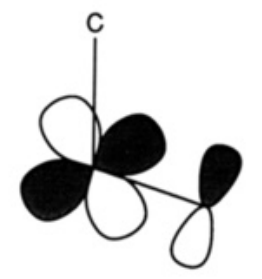

$5 b$

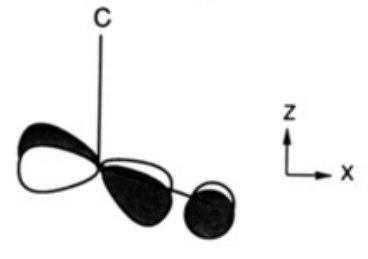

$5 c$ analogues. ${ }^{65}$ Rotational barriers of $17-21 \mathrm{kcal} \mathrm{mol}^{-1}$ have been measured for $\mathrm{Cp}_{2} \mathrm{Ta}(=\mathrm{CHR})(\mathrm{X})$ complexes with use of data obtained from variable-temperature NMR.,63 The differences between the $\mathrm{Cp}_{2} \mathrm{M}$ and $\mathrm{H}_{2} \mathrm{M}$ barriers apparently arise from the strong $\pi$ interaction between the rings and the metal. ${ }^{72,73}$

c. High-Valent, Lewis Acid Free Metathesis Catalysts. Carbenes have been implicated in the olefin metathesis reaction since the seminal work of Herrison and Chauvin in the early 1970 s. $^{25}$ Many of the early metathesis catalysts were poorly characterized mixtures. ${ }^{22-26,74,75}$ Schrock et al. ${ }^{23,32,36}$ and others ${ }^{34,36 j, 76,77}$ have recently synthesized a family of well-characterized, high-valent alkylidene complexes for use as olefin metathesis catalysts. The minimum-energy geometries for the metathesis catalyst models, $\mathbf{4}$, were calculated with both basis sets A and B (Table III) under the constraint of $C_{s}$ symmetry. All of the alkylidene complexes maintain a distorted-tetrahedral coordination environment about the central metal atom. Evidence for the bonding as shown in $\mathbf{4}(\mathrm{M}=\mathrm{C}$ double bond, $\mathrm{M} \equiv \mathrm{N}$ triple bond) is provided by an analysis of the wave functions obtained for the minima and the geometries about the $\mathrm{C}$ (trigonal planar) and $\mathbf{N}$ (linear). There are three $\pi$ pseudosymmetry metal $\mathrm{d}$ orbitals (corresponding to the $t_{2}$ set of $T_{d}$ symmetry). Since these complexes are formally $d^{0}$, the most favorable conformation for the $\pi$-bonding ligands will be that which allows for maximum in-phase bonding between the metal $\mathrm{d} \pi$ and the ligand $\mathrm{p} \pi$ orbitals without having the ligands compete for the $d \pi$ orbitals. If the $\mathrm{M}, \mathrm{C}$, and $\mathrm{N}$ atoms lie in the $x z$ plane with the metal at the origin and carbon along the positive $z$ axis, 4 , then the carbon $\mathrm{p} \pi$ will interact with the $\mathrm{d}_{y z}, 5 \mathrm{a}$. The $\mathrm{N}_{\perp}\left(\approx \mathrm{N} \mathrm{p}_{x}\right)$ and $\mathrm{p}_{\|}\left(\approx \mathrm{N}_{z}\right)$

(72) See refs 12c, 12d, and 60 for a discussion of this point.

(73) The rotational barrier for the $\mathrm{TaCp}\left(\mathrm{CH}_{2}\right)$ Me complex is calculated to be $28 \mathrm{kcal} \mathrm{mol}^{-1}$ at the relativistic extended Huckel level of theory. This is in reasonable agreement with the experimentally determined value $e^{4.63}$ of $\geq 21$ kcal mol-1. In contrast to this $\mathrm{H}_{3} \mathrm{TaCH}_{2}$ and $\mathrm{H}_{3} \mathrm{NbCH}_{2}$ are calculated to have rotational barriers of less than $1 \mathrm{kcal} \mathrm{mol}^{-1}$ by use of both relativistic Extended Hũckel and $\mathrm{ab}$ initio wave functions. These rotational barriers were calculated with the program PPITEREX (kindly provided by P. Pyykkō, Helsinki) and by keeping all geometric parameters frozen except for the methylene torsional angle. Lauher and Hoffman ${ }^{60}$ have used EHT to calculate a rotational barrier of $28 \mathrm{kcal} \mathrm{mol}^{-1}$ in the isoelectronic $\mathrm{TiC}_{2}\left(\mathrm{CH}_{2}\right) \mathrm{Me}^{-}$complex.

(74) Mocella, M. T.; Busch, M. A.; Muetterties, E. L. J. Am. Chem. Soc. 1976, 98, 1283.

(75) Basset, J. M.; Taarit, Y. B.; Coudurier, G.; Praliaud, H. J. Organomet. Chem. 1974, 74, 167.

(76) (a) Ginsburg, E. J.; Gorman, C. B.; Marder, S. R.; Grubbs, R. H. J. Am. Chem. Soc. 1989, 111, 7621. (b) Swager, T. M.; Grubbs, R. H. J. Am. Chem. Soc. 1989, 111, 4413.

(77) (a) Kress, J.; Osborn, J. A. J. Am. Chem. Soc. 1983, 105, 6346. (b) Kress, J.; Osborn, J. A.; Greene, R. M. E.; Ivin, K. J.; Rooney, R. R. J. Am. Chem. Soc. 1987, 109, 899. 
Table III. HF Geometries of High-Valent, Metathesis Catalyst Models ${ }^{a, b}$

\begin{tabular}{llll}
\hline & \multicolumn{1}{c}{ Mo } & \multicolumn{1}{c}{ W } & \multicolumn{1}{c}{ Re } \\
\hline $\mathrm{M}-\mathrm{C}^{c}$ & $1.90(1.88)$ & $2.02(1.89)$ & $1.99(1.88)$ \\
$\mathrm{C}-\mathrm{H}_{3}$ & $1.08(1.09)$ & $1.08(1.09)$ & $1.08(1.09)$ \\
$\mathrm{C}-\mathrm{H}_{4}$ & $1.07(1.08)$ & $1.07(1.08)$ & $1.07(1.08)$ \\
$\mathrm{M}-\mathrm{O}$ & $1.87(1.90)$ & $2.09(1.90)$ & $2.09(1.91)$ \\
$\mathrm{O}-\mathrm{H}$ & $0.96(0.96)$ & $0.96(0.96)$ & $0.96(0.96)$ \\
$\mathrm{M}-\mathrm{X}^{d}$ & $1.67(1.71)$ & $1.88(1.72)$ & $1.78(1.70)$ \\
$\mathrm{X}-\mathrm{H}$ & $1.00(1.01)$ & $1.00(1.00)$ & $1.06(1.07)$ \\
$\mathrm{C}-\mathrm{M}-\mathrm{X}$ & $102(102)$ & $103(103)$ & $95(97)$ \\
$\mathrm{X}-\mathrm{M}-\mathrm{O}$ & $117(116)$ & $116(115)$ & $113(112)$ \\
$\mathrm{O}-\mathrm{M}-\mathrm{O}$ & $105(108)$ & $106(107)$ & $116(113)$ \\
$\mathrm{O}-\mathrm{M}-\mathrm{C}$ & $108(107)$ & $108(108)$ & $109(110)$ \\
$\mathrm{M}-\mathrm{C}-\mathrm{H}_{3}$ & $120(115)$ & $120(115)$ & $116(113)$ \\
$\mathrm{M}-\mathrm{C}-\mathrm{H}_{4}$ & $128(130)$ & $125(131)$ & $129(132)$ \\
$\nu\left(\mathrm{C}-\mathrm{H}_{3}\right)^{c}$ & $3213(3218)$ & $3271(3199)$ & $3254(3189)$ \\
$\nu\left(\mathrm{C}-\mathrm{H}_{4}\right)$ & $3350(3372)$ & $3381(3371)$ & $3409(3378)$ \\
$\nu(\mathrm{M}-\mathrm{C})$ & $693(868)$ & $760(898)$ & $796(901)$ \\
$\nu(\mathrm{M}-\mathrm{X})$ & $950(1120)$ & $952(1144)$ & $1023(1201)$ \\
$\nu(\mathrm{M}-\mathrm{O})$ & $835(728)$ & $724(733)$ & $713(714)$ \\
$\mathrm{ZPE}$ & $43.2(42.6)$ & $41.9(43.0)$ & $42.6(43.1)$ \\
\hline
\end{tabular}

a Basis A, basis B (in parentheses). See text for further details about the basis sets employed. ${ }^{b}$ The geometries for the $\mathrm{W}$ and Mo complexes correspond to minima (i.e. their hessians are positive definite), the $\mathrm{Re}$ complex is a transition state. The imaginary frequency (161i) for the $\mathrm{Re}$ complex corresponds to a change in the $\mathrm{H}-\mathrm{O}-\mathrm{Re}=\mathrm{C}$ torsional angle as well as an additional motion which will serve to lower the overall symmetry from $C_{s}$ to $C_{1}$. The Re-alkylidene complex is a minimum at the smaller basis set and the hydroxyl protons point "downward" away from the carbene moiety as shown in 8.

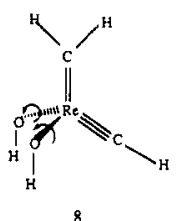

rotation of hydroxyl groups in the $C_{s}$ transition state of the Re alkylidene complex (basis $B$ )

'Bond distances in $A$; bond angles in deg; energy in hartrees; ZPE in $\mathrm{kcal} \mathrm{mol}{ }^{-1} ; \nu(M-C)$ in $\mathrm{cm}^{-1}$. The atom $X$ is $C$ in the $R e$ complex and $\mathrm{N}$ in the $M o$ and $\mathrm{W}$ complexes. 'Intrinsic stretching frequencies calculated with the normal coordinate analysis formalism described in: Boatz, J. A.; Gordon, M. S. J. Phys. Chem. 1989, 93, 1819.

interact with metal $A O s$ which are primarily $\mathrm{d}_{x z}(5 \mathbf{b})$ and $\mathrm{d}_{x y}(\mathbf{5 c})$, respectively.

For the $W$ and Re complexes switching from basis $A$ to basis $B$ once again causes a significant shortening of those bonds involving the metal. The metal-ligand bond lengths calculated with basis $B$ are closer to reported values for model complexes. Two distorted-tetrahedral tungsten complexes with the general formula $\mathrm{W}(=\mathrm{CHR})\left(\mathrm{OR}^{\prime}\right)_{2}(\mathrm{NAr})$ have been structurally characterized by $\mathrm{X}$-ray diffraction techniques, $236,36 a, j$ with reported $\mathrm{W}=\mathrm{C}$ bond lengths ranging from 1.86 to $1.89 \AA .236,366$, The calculated $W=C$ equilibrium bond length with use of basis $B(1.89 \AA)$ is in excellent agreement with the reported values. The equilibrium $W-O$ and $\mathrm{W} \equiv \mathbf{N}$ (basis $\mathrm{B}$ ) bond lengths are 1.90 and $1.71 \AA$, respectively, compared with the experimental values of $1.87-1.90 \AA$ and 1.71-1.75 $\AA .36 \mathrm{a}$ (The calculated bond lengths and bond angles between the heavy atoms with use of basis B are summarized for the tungsten complex in 6 . Values in parentheses are the averages of the reported experimental values. ${ }^{36 a}$ ) The agreement is, in general, excellent: calculated and experimental bond lengths concur to within $0.02 \AA$ and angles agree within $3^{\circ}$. Bonds between the hydrogen atoms and the heavy atoms are in accord with the usual values. ${ }^{78}$ Although a crystal structure for a four-coordinate, Mo alkylidene complex similar to those reported above for the $W$ alkylidene complex has not been reported, the

(78) (a) Weast, R. C., Ed. Handbook of Chemistry and Physics; CRC Press: Boca Raton, 1983; p F-171. (b) Huhecy, J. E. Inorganic Chemistry, 3rd ed.; Harper \& Row: New York, 1983.
Chart VI. Comparison between Calculated (Basis B) and Experimental (in parentheses) Geometric Parameters for $\mathrm{W}(\mathrm{OH})_{2}(\mathrm{NH})\left(\mathrm{CH}_{2}\right)$

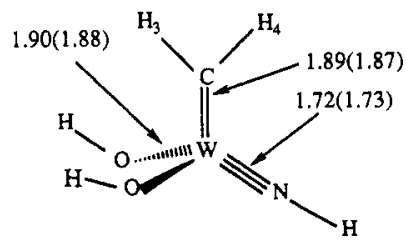

$$
\begin{aligned}
& \text { Angles (degrees) } \\
& \text { O-W-O }=107(110) \\
& \text { O-W-C }=108(110) \\
& \text { O-W.N }=115(112) \\
& \text { C-W.N }=103(103)
\end{aligned}
$$$$
6
$$

Chart VII. Mo Alkylidene Complex which Has Been Recently Characterized by X-ray Diffraction Techniques

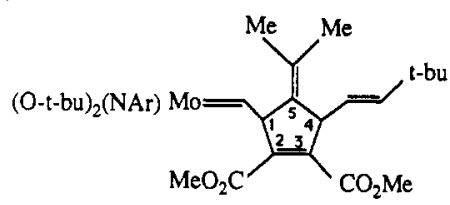

7

unit cell for $\mathrm{Mo}(\mathrm{CH}-t-\mathrm{Bu})(\mathrm{NAr})(\mathrm{O}-\mathrm{t}-\mathrm{Bu})_{2}$ and that for its tungsten analogue have been measured and shown to be identical. Thus it is presumed that the $W$ and Mo complexes are isostructural. ${ }^{79 a}$ The calculated minima (basis B) for the Mo alkylidene and $\mathrm{W}$ alkylidene complexes possess similar geometries. This is expected in light of their nearly identical ionic radii $\left(r_{\text {ion }}\left(W^{6+}(\right.\right.$ coordination number 4$\left.)\right)=0.56 \AA_{;} r_{\text {ion }}\left(\mathrm{Mo}^{6+}(\right.$ coordination number 4$))=0.55 \AA)$, covalent radii $\left(r_{\text {cov }}(W)=1.46\right.$ $\left.\AA ; r_{c o v}(\mathrm{Mo})=1.45 \AA\right)$, and electronegativities $\left(\chi_{W}=2.20\right.$ and $\left.\chi_{M_{0}}=2.36\right) .{ }^{57 \mathrm{a}}$ A more crowded Mo alkylidene complex, 7 , has been recently characterized and its crystal structure reported. 4,796 The experimental (values calculated by basis B in parentheses) $\mathrm{Mo}=\mathrm{C}, \mathrm{Mo}-\mathrm{O}$, and $\mathrm{Mo}=\mathrm{N}$ bond lengths are $1.88(1.88), 1.87$ (1.90), and $1.73 \AA(1.71 \AA)$, respectively.

The $R=C(1.87 \AA$, basis $B)$ and $R e=C(1.70 \AA$, basis $B)$ bond lengths are in reasonable agreement with those reported for the complex $\operatorname{ReI}_{2}(\mathrm{py})_{2}\left(\equiv \mathrm{CCMe}_{3}\right)\left(=\mathrm{CHCMe}_{3}\right)-r_{\mathrm{e}}(\mathrm{Re}=\mathrm{C})=1.87$ $\AA, r_{\mathrm{e}}(\mathrm{Re} \equiv \mathrm{C})=1.74 \AA$. One must be careful, however, when comparing bond lengths for metals having different coordination numbers; for example, the ionic radius of $\mathrm{Re}^{+7}$ is $0.52 \AA$ for a coordination number of four, but it increases substantially to 0.67 $\AA$ for a coordination number of six. ${ }^{78 b}$ Also, unlike the Mo and W complexes, the stationary point for the Re alkylidene complex with $C_{s}$ symmetry does not correspond to a minimum (for basis B) but is a transition state. The imaginary mode for the Realkylidene, $C_{s}$ transition state corresponds to rotation about the $\operatorname{Re}-\mathrm{O}$ bonds as well as motion which will lower the $C_{s}$ symmetry of the molecule. This suggests that the Re complex may be considerably more distorted in comparison to the $\mathrm{W}$ and Mo catalysts.

Limited vibrational data are available for multiply bonded ligands. The vibrational frequencies of transition-metal complexes are often very dependent on coordination geometry and the ligand environment. Nugent and Haymore, in their review of transition-metal imido complexes, ${ }^{808}$ report $\mathrm{W}=\mathrm{N}$ stretches for fourcoordinate, terminal imido complexes of the form $W O(X)(Y)$ (NR) $[\mathrm{X}=\mathrm{Y}=\mathrm{Cl}$, NHR, OEt; $\mathrm{R}=\mathrm{Me}, \mathrm{Et}, n-\mathrm{Pr}]$ in the range $950-975 \mathrm{~cm}^{-1}$. The bis-imido complex Mo(O-t-Bu $)_{2}(\mathrm{NPh})_{2}$ has a characteristic IR band at $1310 \mathrm{~cm}^{-1}$ which shifts to $1280 \mathrm{~cm}^{-1}$

(79) (a) Schrock, R. R. Personal communication. (b) A preliminary account of the characterization of 7 has been reported in ref $23 \mathrm{~b}$ as well as in Bazan, G. C.; Khosravi, E.; Schrock, R. R.; Feast, W. J.; Gibson, V. C.; O'Regan, M. B.; Thomas, J. K.; Davis, W. M. J. Am. Chem. Soc. 1990, I12, 8378. 
a

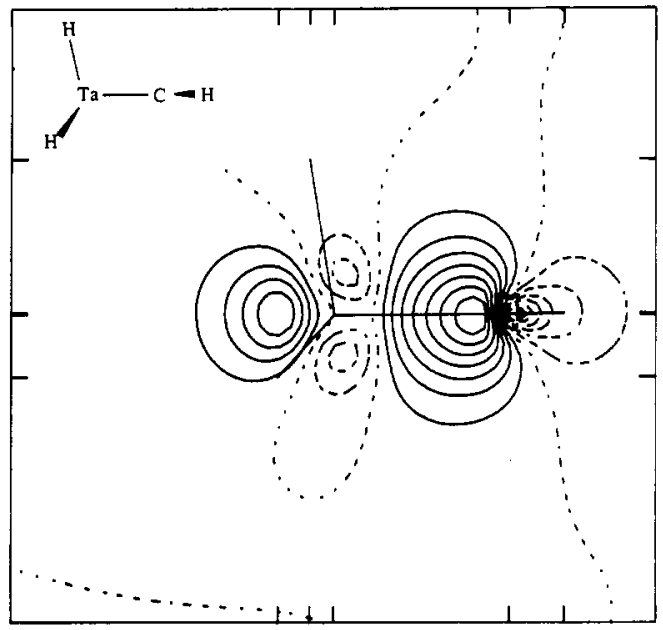

c

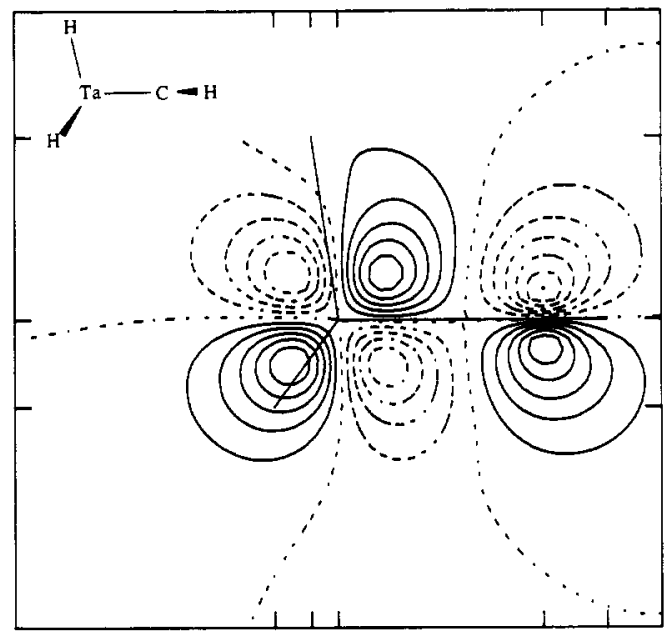

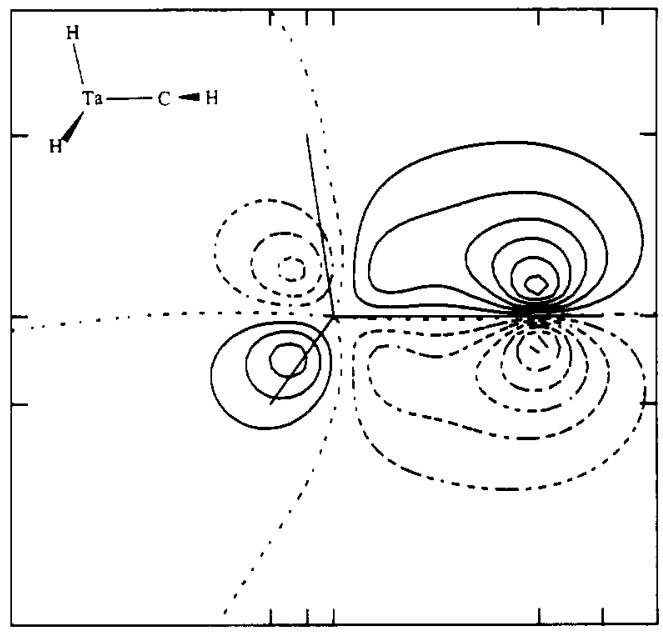

d

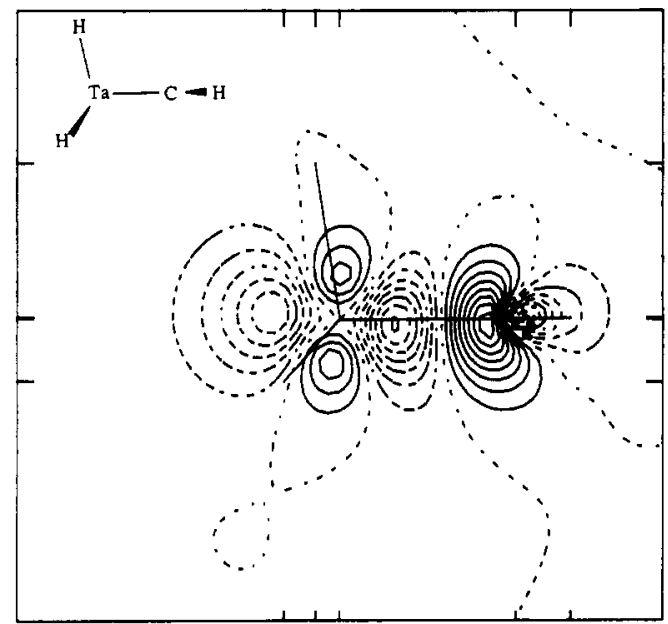

Figure 1. The MOs for the staggered conformation of $\mathrm{H}_{3} \mathrm{TaCH}_{2}$ (calculated with basis $\mathrm{B}+$ at the basis $\mathrm{B}+$ minimum) are plotted in the $C_{3}$ plane for (a) $\mathrm{Ta}-\mathrm{C} \sigma$, (b) $\mathrm{Ta}-\mathrm{C} \pi$, (c) $\mathrm{Ta}-\mathrm{C} \pi^{*}$, and (d) $\mathrm{Ta}-\mathrm{C} \sigma^{*}$. The lowest magnitude contour shown is $0.05 \mathrm{Bohr}^{-3 / 2}$; the increment between successive contour lines is $0.05 \mathrm{Bohr}^{-3 / 2}$. The relative positions of the atoms are shown in the upper, left-hand corner.

upon incorporation of ${ }^{15} \mathrm{~N}$ into the complex. ${ }^{80 \mathrm{~b}}$ The calculated MN frequencies for Mo and $W$ are 1126 and $1144 \mathrm{~cm}^{-1}$, respectively. Scaling factors to account for the effects of electron correlation are often applied to the calculation of ab initio frequencies. ${ }^{81}$ Multiplying the previously calculated $\omega_{e}$ by 0.89 yields stretching frequencies of $1002 \mathrm{~cm}^{-1}$ for the molybdenum alkylidene complex and $1018 \mathrm{~cm}^{-1}$ for the tungsten alkylidene complex.

2. Resonance Contributors to Alkylidene Complexes. Much of the debate concerning the reactivity of carbene complexes, and those reactions in which carbenes are thought to be the active species, has been couched in terms of the direction of the po-

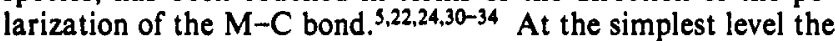
bonding can be described as being comprised of the three resonance structures shown in eq 4 . In eq 4 the usual notation of a straight

$$
\mathrm{M}=\mathrm{+q}=\stackrel{+q+1}{=} \mathrm{M}_{\mathrm{b}}^{-1} \stackrel{+q-1}{=} \stackrel{\mathrm{M}}{=} \mathrm{C}^{+1}
$$

line representing an approximately covalent bond and an arrow representing a coordinate or dative bond has been used. In resonance structure a the unhybridized $2 \mathrm{p} \pi$ atomic orbital on the carbon shares a pair of electrons with the correct symmetry $d \pi$ orbital on the metal fragment. In resonance structure $b$ the same

(80) (a) Kuznetsova, M.; Podzolko, Yu. G.; Buslaev, Yu. A. Russ. J. Inorg. Chem. 1969, 14, 393 quoted in Nugent, W. A.; Haymore, B. L. Coord. Chem. Rev. 1980, 31, 123. (b) Chisolm, M. H.; Folting, K.; Huffmann, J. C.; Ratermann, A. L. Inorg. Chem. 1982, 21, 978 quoted in ref 1, p 124.

(81) Pople, J. A.; Schlegel, H. B.: Krishnan, R.: DeFrees, D. F.; Binkley, J. S.: Frisch, M. J.: Whiteside, R.: Hout, R. F.; Hehre, W. J. Int. J. Quantum Chem., Proc. Sanibel Symp. 1981, 15, 269. carbon $\mathrm{AO}$ donates two electrons to the now vacant $\mathrm{d} \pi$ orbital. Going from resonance structure a to $b$ can be regarded as a metal-to-ligand charge transfer (MLCT); there is a one-electron reduction of the ligand while the metal formal oxidation state increases by one. In resonance structure $c$ the situation is the reverse of that found in $b$ and now the $d \pi$ acts as the donor orbital and the $\mathrm{C} p \pi$ is the acceptor orbital. In molecular orbital terms, the ground-state wave function of the alkylidene complex will be a linear combination of these (and many other) electronic con. figurations; resonance structures which include the $\mathrm{M}-\mathrm{C} \sigma$ bond, or any of the other $\sigma$ bonds, have not even been considered above. ${ }^{82}$ When the above simple description of the metal-carbene bond is used, the explanation of the nucleophilicity of the coordinated carbon in the Schrock-type alkylidene complexes is usually explained in terms of a larger contribution, in relative terms, from resonance structures with the polarization shown in $b$ than is found in the Fischer-type complexes.

Given the fact that much of the discussion concerning carbene reactivity has been presented in terms of the predominance of one resonance structure over the others or "the major resonance contributor" ${ }^{30}$ it would be beneficial if the relative amounts of the important resonance structures could be put on a more quantitative footing. Ideally one would like to carry out a calculation on all the resonance structures that can be generated within a given active space. A reasonable choice of a suitable active space for describing the $\mathrm{M}-\mathrm{C}$ bond of alkylidene complexes

(82) The distorted carbenes in which the $\mathrm{M}=\mathrm{C}-\mathrm{H}$ angle is less than $90^{\circ}$ have been discussed ${ }^{12 \mathrm{a}}$ in terms of resonance structures involving the $\mathrm{CH}$ bond $\left(\mathrm{L}_{n} \mathrm{M}=\mathrm{C}(\mathrm{R}) \mathrm{H} \leftrightarrow \mathrm{L}_{n} \mathrm{~L} \equiv \mathrm{C}(\mathrm{R})^{+} \mathrm{H}^{-}\right)$. 
Scheme I. Generation of "Resonance Structures" from Canonical MOs

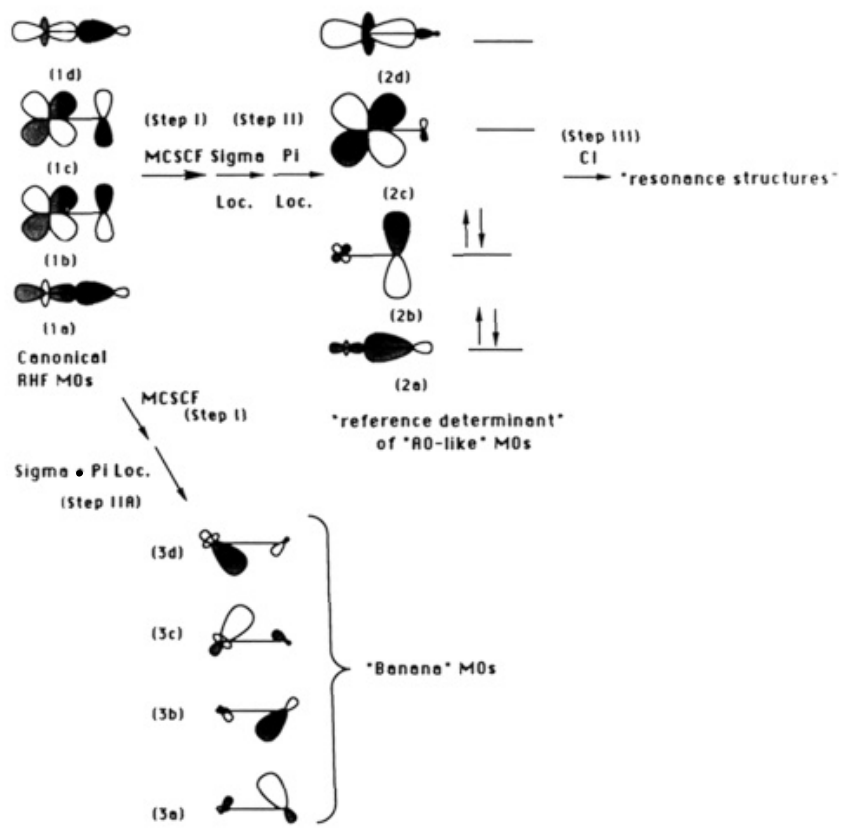

would comprise a metal $\sigma$ hybrid orbital and $\mathrm{d} \pi$ orbital (with perhaps some mixing in of $(n+1) \mathrm{p} \pi$ character) as well as the carbon $\sigma$ hybrid orbital $\left(\approx \mathrm{sp}^{2}\right)$ and $\mathrm{p} \pi \mathrm{AO}$. In an MO calculation the minimum four orbitals which are needed to describe the $\mathrm{M}-\mathrm{C}$ bond are the $\sigma, \pi, \sigma^{*}$, and $\pi^{*}$. These MOs have familiar shapes and representative examples are plotted in Figure 1 for the staggered conformation of $\mathrm{H}_{3} \mathrm{TaCH}_{2}$ (basis $\mathrm{B}+$ ).

Several approaches for transforming the delocalized canonical MOs obtained from molecular orbital calculations into localized orbitals which correspond more closely to the chemists' notion of discrete two-electron bonds have been developed. ${ }^{50,83}$ Only MOs that have the same occupation number can be mixed to obtain localized MOs. For closed-shell compounds this means that one can mix occupied MOs with other occupied MOs and virtual MOs with other virtual MOs. If the M-C $\sigma$ and $\pi$ bonding MOs are localized bent, "banana" bonds are obtained as discussed by Marynick and Kirkpatrick. ${ }^{17,84}$ If one goes beyond the Hartree-Fock single-determinant description of the molecule then it is possible to localize MOs within a given active space as long as all possible spin-adapted configurations which can be constructed from the active electrons are included, i.e. a CASSCF (complete active space self-consistent field) ${ }^{85 a}$ or FORS (full optimized reaction space $)^{85 b}$ wave function is required. Localization of the MCSCF (multi-configuration self-consistent field)-optimized MOs yields orbitals that are highly localized or "AO-like" on either end of the $\mathrm{M}-\mathrm{C}$ bond. The localized MCSCF-optimized orbitals can then be used as a basis for generating "resonance structures" by the use of configuration interaction $(\mathrm{CI})$ from a suitably chosen reference wave function. Similar approaches have been employed by various workers and used to study main-group compounds. ${ }^{856,86}$ This method is to be contrasted to the spin-coupled valence bond method of Cooper et al. ${ }^{87}$ in which the active orbitals are nonorthogonal. Although very atomic in nature the localized orbitals

(83) Edmiston, C.; Ruedenberg, K. Rev. Mod. Phys. 1965, 53, 457.

(84) Localized "banana" bonds in ethylene and other organic $\pi$ systems have been discussed in England, W.; Gordon, M. S. J. Am. Chem. Soc. 1969, 91,6864 .

(85) (a) Roos, B. In Advances in Chemical Physics; Lawley, K. P., Ed.; Wiley: New York, 1987; Vol. 69, Part II, p 399. (b) Ruedenberg, K.; Schmidt, M. W.; Dombek, M. M.; Elbert, S. T. Chem. Phys. 1982, 71, 41, 51,65 .

(86) (a) Lam, B.; Schmidt, M. W.; Ruedenberg, K. J. Phys. Chem. 1985, 89, 2221. (b) McDouall, J. J. W.; Robb, M. A. Chem. Phys. Lett. 1986, 132 , 319.

(87) Cooper, D. L.; Gerratt, J.; Raimondi, M. Adv. Chem. Phys. 1987, 27 (Part II), 319. are still MOs and are, therefore, orthogonal to the other MOs. The localized MOs possess small "tails" on the other atoms (typically $<2 \%$ of the orbital electron density) in order to maintain their orthogonality to each other. The less atomic-like the localized orbitals become, the greater the difference will be between this approach and a valence bond calculation.

The method for obtaining the localized MCSCF-optimized orbitals is as follows.

(1) The RHF, single-determinant wave function is calculated and the MOs that correspond most closely to the M-C $\sigma, \pi, \pi^{*}$, and $\sigma^{*}$ (Figure 1, a-d and 1a-d in Scheme I) are identified. A 4-orbital, 4-electron FORS-MCSCF calculation is then performed to obtain a starting set of orbitals for the localization procedure. All twenty configurations $\left(\sigma^{2} \pi^{2}, \sigma^{2} \pi^{* 2}\right.$, etc.) that can be obtained from arranging four electrons in four MOs are included in the FORS-MCSCF wave function. This first step (step I in Scheme I) is important because the MCSCF procedure provides improved orbitals, particularly for those MOs that were unoccupied in the RHF calculation. For example, simple frontier orbital considerations lead one to expect that the M-C $\pi^{*} \mathrm{MO}$ will be predominantly comprised of an out-of-phase combination of the C $2 \mathrm{p} \pi \mathrm{AO}$ and the $\mathrm{M} n \mathrm{~d} \pi \mathrm{AO}$ with some mixing in of the correct symmetry $\mathrm{M}(n+1) \mathrm{p} \pi$ in such a way as to make the M-C $\pi^{*}$ lower in energy. The $\pi^{*}$ virtual MO obtained from an RHF calculation is largely $(n+1) \mathrm{p} \pi$ in character with only small amounts of $\mathrm{M} n \mathrm{~d} \pi$ and $\mathrm{C} 2 \mathrm{p} \pi$ mixed in. After carrying out the $4 \times 4$ MCSCF calculation, the $\pi^{*} \mathrm{MO}$ is almost evenly distributed between the $\mathrm{M}$ and the $\mathrm{C}$ and the amount of $(n+1)$ p $\pi$ character is greatly reduced while $\mathrm{d} \pi$ character is increased. The MCSCF procedure also has the benefit that it tends to localize the MOs somewhat. In the RHF calculation the M-C $\sigma$ MO usually has a significant admixture $(\approx 10 \%$ to $20 \%)$ of the in-phase combination of the $\mathrm{M}-\mathrm{H} \sigma$ bonds.

(2) After carrying out the $4 \times 4 \mathrm{MCSCF}$ procedure, the MCSCF-optimized orbitals are localized to yield "AO-like" MOs. This is step II in Scheme I. The four MCSCF-optimized MOs (similar in shape and size to those shown in Figure 1 and represented pictorially by la-d in Scheme I) are subjected to the Boys localization procedure twice. First, the $\mathrm{M}-\mathrm{C} \sigma$ and $\sigma^{*}$ MCSCF-optimized MOs are localized to yield two MOs. One of these MOs is predominantly localized on the carbon $\left(\approx{ }^{\text {" }} \mathrm{sp}^{2 n}\right)$ and the other is predominantly localized on the metal $(\approx \mathrm{d} \sigma$ AO with some s and $\mathrm{p} \sigma$ character) as shown in Figure 2a,d. Second, the $\pi$ and $\pi^{*}$ MCSCF-optimized MOs are localized. Once again, one of the resulting localized MOs is largely situated on the metal $(\mathrm{d} \pi)$ while the other is primarily $\mathrm{C} 2 \mathrm{p} \pi$ in nature as depicted in Figure 2b,c.

The localized MOs are plotted in Figure 2 for the staggered Ta alkylidene complex with basis B+ and are depicted graphically by $2 a-d$ in Scheme I. If all four MCSCF-optimized MOs are localized at the same time, mixing of the $\sigma$ and $\pi$ orbitals occurs to yield bent, "banana" orbitals (3a-d in Scheme I) on the C and similarly shaped orbitals on the metal. This is depicted as step IIa in Scheme I.

(3) By using the localized MOs as a basis, a $4 \times 4 \mathrm{CI}$ is used to generate "resonance structures" and their relative weight in the ground-state wave function, $\Psi$ (see step III in Scheme I). The 20 spin-adapted configurations generated are shown schematically in Scheme II. The reference determinant in all of the MC/ LMO/CI calculations is $\left|\sigma_{C}{ }^{2} \pi_{C}^{2} \pi_{M}^{0} \sigma_{M}\right\rangle \equiv \mathrm{M}: C \equiv|2200\rangle$. This "resonance structure" is represented pictorially as I in Scheme II. The $|2200\rangle$ configuration corresponds to a $\mathrm{CH}_{2}{ }^{2-}$ ligand coordinatively bonded to a $\mathrm{L}_{n} \mathrm{M}^{2+}$ fragment. This configuration is that used in organometallic electron-counting schemes in which the carbene ligand is considered to be a four-electron donor coordinated to a high-valent transition metal and is most often applied to Schrock-type alkylidene complexes. ${ }^{3}$ The configuration generated by excitation of two electrons from $C \pi$ to $M \pi, \mid 2020$ ), generates the singlet carbene model ${ }^{7}$ of bonding described by Hall and Taylor (XV in Scheme II). Another double excitation from the $|2200\rangle$ reference determinant yields two |1111 > configurations. There are two $\mid 1111$ ) configurations, since there are two singlet 
Table IV. Calculated Weights of the $\sigma$ and $\pi$ Configurations Comprising Alkylidene Complexes ${ }^{a}$

\begin{tabular}{|c|c|c|c|c|c|c|c|c|c|c|c|c|c|c|}
\hline \multirow{2}{*}{ configuration } & & \multicolumn{6}{|c|}{ basis $\mathrm{B}+$} & \multicolumn{7}{|c|}{ basis $\mathrm{D}^{\prime}$} \\
\hline & & $\overline{T i^{b}}$ & $\mathrm{Zr}^{b}$ & $\mathrm{Hf}^{b}$ & $\mathrm{Nb}^{\mathrm{c}}$ & $\mathrm{Ta}^{c}$ & $\overline{\mathrm{W}^{d}}$ & $T^{b}$ & $\mathrm{Zr}^{b}$ & $\mathrm{Hf}^{b}$ & $\mathrm{Nb}^{\mathrm{c}}$ & $\mathrm{Ta}^{c}$ & Mo & $\mathrm{W}^{d}$ \\
\hline I & $2200\rangle$ & 0.162 & 0.255 & 0.290 & 0.246 & 0.241 & 0.218 & 0.169 & 0.287 & 0.306 & 0.220 & 0.253 & 0.211 & 0.253 \\
\hline II & & 0 & 0 & 0 & -0.101 & -0.026 & 0 & 0 & & 0 & 0.002 & 0.003 & & 0 \\
\hline III & $11201\rangle$ & 0.301 & 0.390 & 0.392 & -0.377 & -0.370 & 0.359 & 300 & .367 & 0.370 & 0.342 & 0.351 & 0.332 & 0.363 \\
\hline IV & 2002) & -0.021 & -0.023 & -0.014 & -0.055 & -0.019 & -0.016 & 0.021 & 0.013 & 0.013 & 0.018 & 0.015 & 0.017 & -0.015 \\
\hline $\mathrm{v}$ & $\mid 1102\}$ & 0 & 0 & 0 & 0.011 & -0.002 & 0 & 0 & 0 & 0 & -0.002 & -0.002 & & \\
\hline VI & 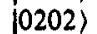 & 0.154 & 0.179 & 0.177 & 0.202 & 0.184 & 0.192 & 128 & .140 & 0.149 & & 0.154 & .160 & 0.173 \\
\hline VII & & 0.6 & 0.555 & 0.558 & 0.492 & 0.530 & 0.516 & .621 & 0.606 & 0.590 & 0.555 & 0.562 & 0.546 & 0.542 \\
\hline VIII & 1 & 0 & 0 & 0 & -0.071 & -0.019 & 0 & 0 & & 0 & 0.000 & -0.002 & 0 & \\
\hline IX & & 0.550 & 0.516 & 0.496 & 0.507 & -0.5 & 0.540 & 0.556 & 0.489 & 0.481 & & & 0.545 & 0.520 \\
\hline $\mathrm{x}$ & & 0 & 0 & 0 & 0.0 & 0.0 & 0 & & & & & 0. & & \\
\hline XI & & 0.248 & 0.243 & 0.235 & -0.279 & -0.251 & 0.258 & 0.232 & 0.224 & 0.226 & & & 0.252 & 0.249 \\
\hline XII & 6 & 0 & 0 & 0 & 0.010 & 0.000 & 0 & 0 & 0 & 0 & & & & 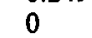 \\
\hline XIII & & 0 & 0 & 0 & & -0 . & 0 & . & & 0 & & & . & 0 \\
\hline XIV & & 0.163 & 0.173 & 0.167 & -0.2 & 0.1 & 0.213 & 0.126 & 0.124 & 0.142 & 0. & 0.162 & 0.181 & 0.185 \\
\hline$X V$ & & 0.268 & 0.256 & 0.250 & 0.260 & 0.273 & 0.270 & 0.282 & 0.266 & 0.268 & 0. & & 0.291 & 0.274 \\
\hline$X V I$ & & 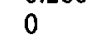 & 0 & 0 & 0.010 & 0.006 & 0 & 0 & & 0 & & & & \\
\hline XVII & & 1 & $-0 . c$ & -0. & -0.0 & -0.0 & -0. & 22 & & & & & & 3 \\
\hline XVIII & & & 0.1 & 0.1 & 0.197 & -0 . & 0.215 & 0.142 & 0.141 & 0.155 & 0. & 0. & 0.198 & 0.193 \\
\hline XIX & 0 & 0 & 0 & 0 & 0.039 & -0.013 & 0 & 0 & 0 & 0 & -0.002 & -0.002 & 0 & 0 \\
\hline & 1002 & 0.029 & 0.031 & 0.030 & 0.057 & 0.042 & 0.048 & 0.016 & 0.016 & 0.022 & & 0.032 & 0.035 & 0.038 \\
\hline IIX & & & 0.32 & 0.30 & 0.3 & 0.34 & 0.36 & 0.36 & 0.29 & 0.28 & & & & \\
\hline$I^{2}+X V^{2} y$ & & 0. & 0. & 0. & 0. & 0. & 0.4 & 0.46 & 0. & 0. & 0. & 0. & 0. & 0. \\
\hline $\mathrm{I}^{2}$ & & 0.4 & 0.5 & 0.5 & 0.4 & 0.48 & 0.44 & 0.50 & 0.58 & 0.58 & 0.47 & 0.50 & 0.45 & 0.49 \\
\hline$\left.\left\{\mathrm{XIV}^{2}+\mathrm{XVIII}\right\}^{2}\right\}^{h}$ & & 0.05 & 0.06 & 0.05 & 0.08 & 0.07 & 0.09 & 0.04 & 0.04 & 0.04 & 0.06 & 0.06 & 0.07 & 0.07 \\
\hline
\end{tabular}

"The $\mathrm{Ti}-, \mathrm{Zr}-$, and $\mathrm{Hf}$-alkylidene complexes are the minima (planar, singlet) obtained with basis set $\mathrm{B}+$. The $\mathrm{Nb}-$ and $\mathrm{Ta}$-alkylidene complexes are the minima (staggered conformation, singlet) obtained with basis set $\mathrm{B}+$. The W-alkylidene is the $C_{5}$ minimum of $\mathrm{W}(\mathrm{OH})_{2}(\mathrm{NH})\left(\mathrm{CH}_{2}\right)$ obtained with basis B. 'Structures given in Table I. 'Structures given in Table II. ${ }^{d}$ Structures given in Table III. ${ }^{e}$ This row shows the sum of the contributions made by the all-covalent configurations, $|1111\rangle$. 'This row shows the sum of the contributions made by the four major neutral resonance structures (i.e. both the metal and the carbon each possess two of the four $M-C \sigma$ and $\pi$ electrons), |1111) (both of them), 10202), and $|2020\rangle$. This row shows the sum of the contributions made by the three major nucleophilic resonance structures, i.e. those configurations (|2200), $|1201\rangle$, and $|2110\rangle)$ in which the carbon is the negative end. ${ }^{h}$ This row shows the sum of the contributions made by the two major electrophilic resonance structures, i.e. those configurations $(\mid 0112)$ and $|1021\rangle)$ in which the carbon is the positive end. 'These weights were calculated with basis $D$ (see text). The weights denoted by " $0^{n}$ have a zero contribution for symmetry reasons. 'These weights were calculated with basis B+ (see text). The d-orbital exponents were left off the $\mathrm{O}$ and $\mathrm{N}$ atoms in the $\mathrm{W}$ complex.

spin-couplings ( $\alpha \beta \alpha \beta$ and $\alpha \alpha \beta \beta)$ for this spatial configuration. This electronic configuration corresponds to covalent $M-C$ bonding. This resonance structure parallels the triplet carbene model of bonding that was described by Hall and Taylor and corresponds to IX and XI in Scheme II. ${ }^{7}$ These and other "resonance structures" are collected in Scheme II. The relative weights of the electronic configurations which contribute to the ground-state wave function of each minimum obtained for the planar group IVB alkylidenes, staggered group VB alkylidenes, and the $C_{s}$ metathesis catalysts are shown in Table IV.

Since it is the $\mathrm{M}-\mathrm{C} \pi$ system which in large part determines the reactivity of the alkylidene species, an alternative approach was used in which the $\mathrm{M}-\mathrm{C} \sigma \mathrm{MO}$ was left in the canonical form and only the M-C $\pi$ and $\pi^{*}$ were subjected to the $\mathrm{MC} / \mathrm{LMO} / \mathrm{CI}$ procedure. This latter calculation yields only three "resonance structures" analogous to those shown in eq 4 . The three resonance structures generated by electron correlation within the $\mathrm{M}-\mathrm{C} \pi$ system will be comparable to configurations III $(\approx$ resonance structure b), XVIII ( $\approx$ resonance structure c), and IX or XI ( $\approx$ resonance structure a). The reference determinant for this latter set of calculations, $|20\rangle$, is $\left|\pi_{C}{ }^{2} \pi_{M}^{0}\right\rangle$. There will only be one covalent configuration since there is only singlet spin coupling $(\alpha \beta-\beta \alpha) / \sqrt{ } 2)$ for a two-electron system.

Two different basis sets were employed in the MC/LMO/CI procedure. For the group IVB and group VB alkylidenes the largest basis set $(\mathrm{B}+)$ was used in order to give as much flexibility in describing the MOs as possible. For the $\mathrm{W}$ alkylidene complex, the SBK valence basis and ECPs were used for the metal, the 3-21G basis set was used for the $\mathrm{N}, \mathrm{H}$, and $\mathrm{O}$ atoms, and the 3-21G(d)+ basis was employed to describe the $\mathrm{C}$. The results using this basis set are collected in Table IV. The large size of basis $\mathrm{B}+$, coupled with the desire to investigate more realistic models of experimentally characterized alkylidene complexes with larger substituents, prompted us to test a smaller basis set in constructing the various electronic configurations. Employing this basis set makes the MCSCF step more computationally tractable
Table V. Calculated Weights of $\pi$ Configurations Compromising Alkylidene Complexes ${ }^{a}$

\begin{tabular}{cccccccc}
\hline & \multicolumn{7}{c}{ basis set $\mathrm{B}+$} \\
\cline { 2 - 8 } config & $\mathrm{Ti}$ & $\mathrm{Zr}$ & $\mathrm{Hf}$ & $\mathrm{Nb}$ & $\mathrm{Ta}$ & $\mathrm{W}$ \\
\hline$|20\rangle$ & 0.288 & 0.426 & 0.475 & 0.368 & 0.419 & 0.404 \\
$11\rangle$ & 0.925 & 0.862 & 0.838 & 0.872 & 0.853 & 0.858 \\
$|02\rangle$ & 0.249 & 0.276 & 0.267 & 0.323 & 0.311 & 0.317 \\
\hline \multicolumn{7}{c}{ basis set $\mathrm{D}$} \\
config & $\mathrm{Ti}$ & $\mathrm{Zr}$ & $\mathrm{Hf}$ & $\mathrm{Nb}$ & $\mathrm{Ta}$ & $\mathrm{Mo}$ & $\mathrm{W}$ \\
\hline$|20\rangle$ & 0.291 & 0.413 & 0.461 & 0.361 & 0.408 & 0.357 & 0.428 \\
$|11\rangle$ & 0.925 & 0.867 & 0.842 & 0.874 & 0.851 & 0.875 & 0.849 \\
$|02\rangle$ & 0.241 & 0.277 & 0.278 & 0.325 & 0.329 & 0.325 & 0.311 \\
\hline
\end{tabular}

${ }^{a}$ The valence basis sets and effective core potentials which comprise basis $\mathrm{D}$ and basis $\mathrm{B}+$ are described more fully in the text.

for the metathesis catalyst models. This basis set employed the HW ECPs and valence basis for the transition metals augmented with an extra $d$ function as specified by Hay (for the first-row transition metals) ${ }^{88}$ and Bauschlicher (for the second-row transition metals). ${ }^{89,90}$ The 3-21G basis set augmented with diffuse and polarization functions was used for the coordinated carbon. The STO-3G all-electron basis set was utilized to describe the heavy atoms, other than the carbene $\mathrm{C}$ and the transition metal, as well as the hydrogen atoms. This basis set will be referred to as $D$. The approach taken here is to describe the $\mathrm{M}=\mathrm{C}$ bond as well as possible while using a minimal basis set to describe the auxiliary ligands. A similar philosophy was successfully implemented by Hall and Taylor in their study of carbene complexes. ${ }^{7}$ This

(88) Hay, P. J. J. Chem. Phys, 1977, 66, 4377.

(89) Bauschlicher, C. W.; Walch, S. P.; Nelin, C. J. J. Chem. Phys. 1983, 79,3600 .

(90) In light of the similar chemical properties of the second- and third-row transition metals it was decided to use the same extra $d$ exponent ${ }^{89}$ for elements in the same group. 

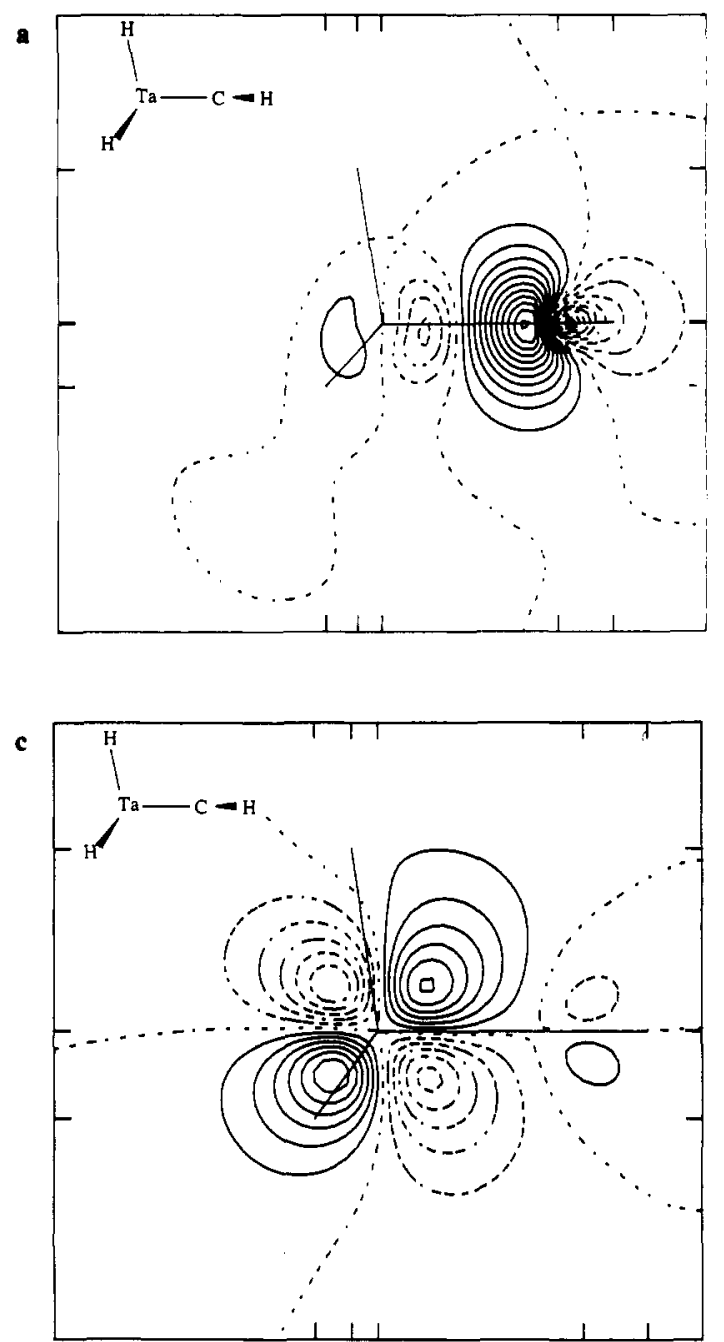
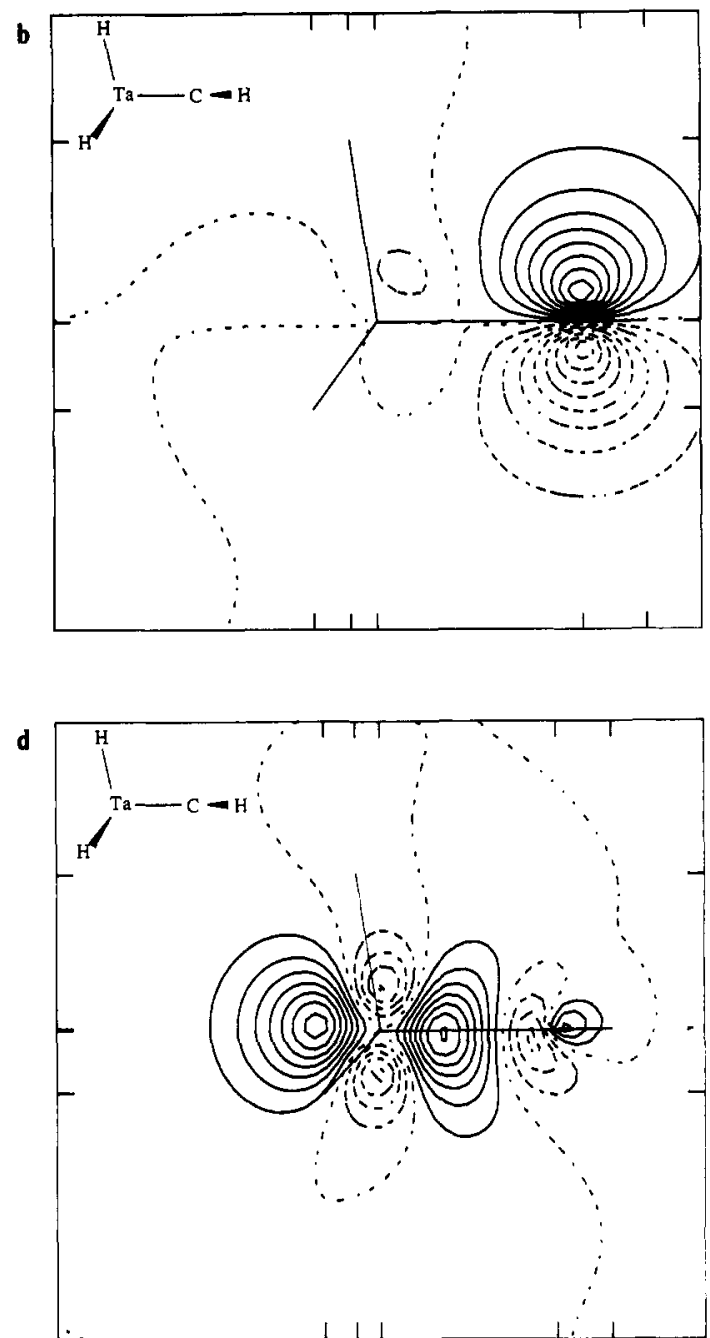

Figure 2. The localized MCSCF-optimized MOs for the staggered conformation of $\mathrm{H}_{3} \mathrm{TaCH}_{2}$ (calculated using Basis $\mathrm{B}+$ at the Basis $\mathrm{B}+$ minimum) are plotted in the $C$, plane for (a) $C \sigma$, (b) $C \pi$, (c) Ta $\pi$, and (d) Ta $\sigma$. The lowest magnitude contour shown is 0.05 Bohr $^{-3 / 2}$; the increment between successive contour lines is $0.05 \mathrm{Bohr}^{-3 / 2}$. The relative positions of the atoms are shown in the upper, left-hand corner.

procedure is also consistent with the "splicing" approach recently reported by Jensen and Gordon. ${ }^{91}$ The $\mathrm{MC} / \mathrm{LMO} / \mathrm{CI}$ procedure does not seem to be excessively basis set dependent as may be seen by comparing the basis $\mathrm{B}+$ and basis $\mathrm{D}$ values in Table IV. Despite the reduction in the size of the basis set very similar results are obtained. The $\pi$ configurations were also generated with basis $\mathrm{B}+$ and $\mathrm{D}$. The calculated weights are listed in Table V.

\section{Discussion}

The resonance structures which contribute to the ground-state wave function of alkylidene complexes can be divided into three categories-nucleophilic (i.e. $\mathrm{L}_{n} \mathrm{M}^{q+} \mathrm{CH}_{2}{ }^{q-}$ ), electrophilic $\left(\mathrm{L}_{n} \mathrm{M}^{q-} \mathrm{CH}_{2}{ }^{q+}\right)$, and neutral $\left(\mathrm{L}_{n} \mathrm{M}^{0} \mathrm{CH}_{2}{ }^{\circ}\right)$. From the data collected in Tables IV and V, the most apparent feature is the similarity of the bonding in the alkylidene complexes regardless of group or row in the periodic table or the ligands attached to the transition metal. In light of the similar reactivity of these complexes it is not surprising that their electronic structures are comparable. The sum of the squares of the dominant "nucleophilic" resonance structures $\left(\mathrm{I}^{2}+\mathrm{III}^{2}+\mathrm{VII}^{2}\right)$ is shown at the bottom of Table IV; they account for roughly one-half of the contributions to the ground-state wave function of the alkylidenes. In contrast, the dominant electrophilic resonance structures (see the row labeled $\mathrm{XIV}^{2}+\mathrm{XVIII}^{2}$ in Table IV) contribute only $5 \%$. Neutral resonance structures, therefore, make up the remaining amount $(\approx 45 \%)$. The $\pi-\mathrm{MC} / \mathrm{LMO} / \mathrm{CI}$ data (see Table V) are also consistent with this analysis: the contribution (the weight squared)

(91) Jensen, J. H.; Gordon, M. S. J. Comp. Chem. 1991, 12, 421. to the ground-state wave function is greater when the metal is polarized in a $\mathrm{L}_{n} \mathrm{M}^{+}-\mathrm{CH}_{2}^{-}$fashion (|20)) than when it is polarized in the opposite sense $(\mid 02)$ or $\left.\mathrm{L}_{n} \mathrm{M}^{-}-\mathrm{CH}_{2}^{+}\right)$. In all cases the dominant resonance structure is the covalently bound one (|11)). The all-covalent resonance structures obtained from the $\sigma \pi$ $\mathrm{MC} / \mathrm{LMO} / \mathrm{CI}$ procedure (IX ${ }^{2}+\mathrm{XI}^{2}$ in Table IV) may also be considered to be nucleophilic. ${ }^{1}$

The same five configurations $(|2110\rangle, 2 *|1111\rangle,|1201\rangle,|2020\rangle$, and $|2200\rangle)$ account for over $90 \%$ of the total contributions to the metal-carbene bond (Table IV). The following analysis is based on the data obtained with basis set $\mathrm{D}$ as described in Table IV. The $\mid 2200$ ) reference determinant, corresponding to coordination of the $\mathrm{CH}_{2}{ }^{2-}$ ligand to a $\mathrm{L}_{n} \mathrm{M}^{2+}$ fragment, makes only a minor contribution to the overall bonding of the alkylidene models studied here. Even though this bonding scheme is often applied to carbene ligands attached to electron-deficient transition metals in the electron-counting formalisms (developed as the organometallic equivalent of Lewis' octet rule $^{3}$ ), the $\sigma \pi \cdot \mathrm{MC} /$ LMO/CI results predict that the contribution of this resonance structure ranges only from $3 \%$ for the titanium complex up to $9 \%$ for the hafnium complex. The $\mid 2200$ ) configuration would be expected to make an even smaller contribution in the Fischer-type carbenes. ${ }^{92}$

According to the analysis of Hall and Taylor, the bonding in high-valent alkylidenes can be best described as arising from the low-spin coupling of a triplet carbene with a triplet transition-metal

(92) Preliminary results for prototypical Fischer carbenes are in agreement with this conclusion. 
Scheme II. Electronic Configurations from $4 \times 4 \mathrm{Cl}$
I

II

III

IU

v

U I

U I

UIII

I H

H

H I

KII

KIII

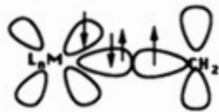

หIV

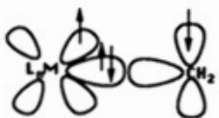

KU

KUI

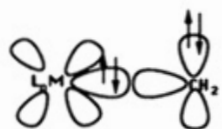

|0202〉

$12110\rangle$

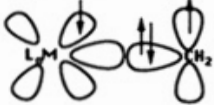

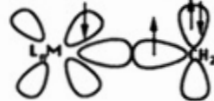

$|1210\rangle$

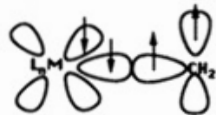

$\mid 11112$

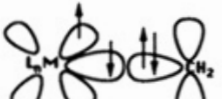

12011

|1111

02112

$11012\rangle$

01122

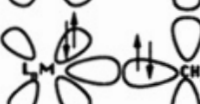

|20202

0220>

RUII

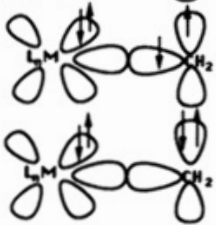

หบ।<smiles>C1=C[As]2CC[As]1C2</smiles>

HIU

кн

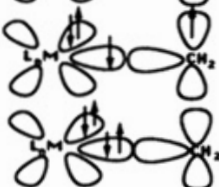

$|0022\rangle$

10022

\section{$M=C$ \\ $M \ldots C$ \\ $\mathrm{M}=\mathrm{C}$ \\ M \\ $M \rightarrow: C$}

$M=C$

$M=C$

$M \cdot C$

$M=c$

M:-C

$\mathrm{M}=\mathrm{c}$

$M:=-C$

$M \div C$

$M=C$

$M=C$

$M-: C$

$\ddot{M} \quad \ddot{c}$

$M=C$

$M \div C$

$M=c$ fragment. ${ }^{7}$ The results of the $\sigma \pi-\mathrm{MC} / \mathrm{LMO} / \mathrm{CI}$ analysis partially support this contention. The contribution from the |1111) configuration IX (corresponding to the triplet-carbene model of bonding) is in all cases studied here either the largest or sec-

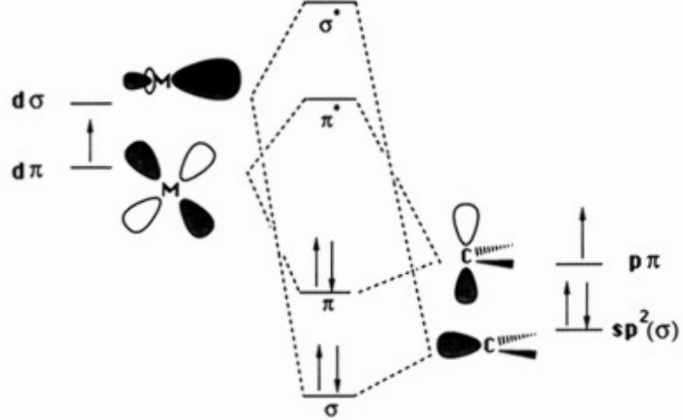

Figure 3. Qualitative orbital interaction diagram between alkylidene and transition-metal fragments.

ond-largest resonance contributor as illustrated in Table IV. The contribution is roughly three times larger for $|1111\rangle$ when compared to $|2020\rangle$. The $|2020\rangle$ configuration corresponds to a $M \vec{\sim} 0$ resonance structure and the singlet-carbene bonding scheme described by Hall and Taylor. ${ }^{7}$ Nonetheless, several other configurations make significant contributions to the wave functions of these species.

The configuration $|1201\rangle$ corresponds to a covalent $\mathrm{M}-\mathrm{C} \sigma$ bond and a dative carbon-to-metal $\pi$ back-bond, $M_{-}^{-}$. This configuration is particularly interesting, because it corresponds to the classical description of phosphorus ylides $\left(\mathrm{R}_{3} \mathrm{P}=\mathrm{CR}_{2} \rightarrow\right.$ $\left.\mathrm{R}_{3} \mathrm{P}_{-}-\mathrm{CR}\right){ }^{65,66}$ The structural similarity between the phosphorus ylides and the group VB alkylidenes was noted above; the $\sigma \pi$ MC/LMO/CI procedure now highlights their chemical similarity. That the group VB alkylidenes should possess similar chemical reactivity to their main group analogues was appreciated very early in the systematic study of the complexes. ${ }^{23 a, 32}$ The |1201) configuration makes an average contribution of $13 \%$ to the groundstate wave functions. This resonance structure will make an important contribution to the nucleophilic character of the high-valent alkylidene complexes.

Several further results obtained from the MC/LMO/CI procedure are of interest; these numbers are the matrix elements derived from the reduced one-particle density matrix or one-matrix, $\gamma(i, j)$, where $i$ and $j$ are the localized metal and carbon orbitals. The diagonal elements of this matrix, $\gamma(i, i)=\rho(i)$, are the electron occupation numbers of orbital $i$. The off-diagonal matrix elements, $\gamma(i, j)$, can be considered to be the bond order between orbitals $i$ and $j$. The one-matrix elements derived from the $\pi$ - and $\sigma \pi$ $\mathrm{MC} / \mathrm{LMO} / \mathrm{CI}$ wave functions are collected in Table VI. An analysis of the diagonal elements reveals that the $\mathrm{M}-\mathrm{C} \sigma$ bond in the model alkylidene complexes is predominantly ionic or dative in nature, while the $\mathrm{M}-\mathrm{C} \pi$ bond is essentially covalent. The $\rho(i)$ values for the carbon $\sigma$ orbital run from a minimum of 1.37 for the Mo and $\mathrm{W}$ alkylidene complexes to a maximum of 1.49 for the $\mathrm{Zr}$ alkylidene. As the $\rho(\mathrm{C} \sigma)$ matrix element approaches a value of 2 the description of the $\mathrm{M}-\mathrm{C} \sigma$ interaction can be more accurately described as an ionic or dative bond. The one-matrix elements for the $\pi$ orbitals are much closer to one for both the metal and carbon with use of either the $\pi$ - or $\sigma \pi-\mathrm{MC} / \mathrm{LMO} / \mathrm{CI}$ procedures. Electronic configurations with a covalent $\sigma$ bond, i.e. one electron in $\sigma_{\mathrm{M}}$ and one electron in $\sigma_{\mathrm{C}}$, contribute $50 \%$ to the ground-state wave function of the various alkylidenes studied. In contrast, resonance structures with a covalent $\pi$ bond contribute about $67 \%$ to the total $\pi$ wave function. That the $\mathrm{M}-\mathrm{C} \sigma$ bonding is more ionic than the $\mathrm{M}-\mathrm{C} \pi$ bonding is consistent with simple frontier orbital considerations. The $\mathrm{M}-\mathrm{C} \sigma$ interactions arise from donation of electron pairs from the carbon $\sigma$ donor orbital into the vacant metal $\sigma$ acceptor orbital. The M-C $\pi$ bonding results from interaction between the higher energy (relative to the carbene $\sigma$ ) carbene $\mathrm{p} \pi$ and the lower energy (relative to the metal $\sigma$ ) $\mathrm{d} \pi$ orbitals, Figure 3. As a result the energy match between the $\pi$ pseudosymmetry orbitals will be better and the bonding more covalent than is found for the $\sigma$ counterpart (Figure 3). This depiction of the metal-carbon interaction as arising from a dative carbon to metal $\sigma$ bond and a covalent $\mathrm{M}-\mathrm{C} \pi$ bond can be best represented by the $|2110\rangle$ configuration or a $M_{-}^{-} C$ resonance 
Table VI. One-Particle Reduced Density Matrix Elements Derived from the MC/LMO/CI Procedure (Basis D) ${ }^{a}$

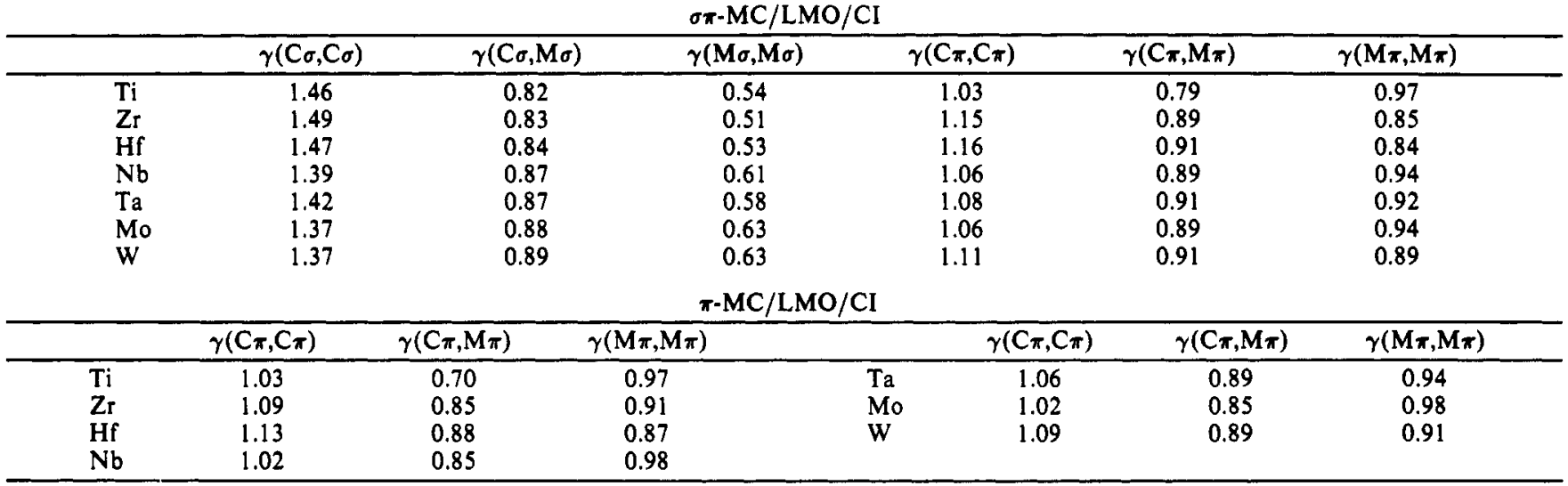

a These matrix elements were calculated with basis D (see text).

structure. This description of the metal-carbene interaction has heretofore not entered into the discussion of these complexes; thus it is striking that $|2110\rangle$ is consistently the largest contributor.

The striking result that ionic resonance structures make a large contribution to the metal-carbon bonding in alkylidenes appears to be independent of the basis set. Note that these results are consistent with previous valence bond calculations on the "covalent" $\mathrm{CC}$ bond in ethylene. ${ }^{93}$ In the latter, it has been found that ionic $\pi$ structures contribute roughly $25 \%$ to the ground state. The $\mathrm{MC} / \mathrm{LMO} / \mathrm{CI}$ method used here (which may be thought of as an MCSCF analogue of these valence bond calculations) agrees with this conclusion.

\section{Summary}

In this paper the results of $a b$ initio calculations are reported for prototypical high-valent, alkylidene complexes. The minima which are characterized compare favorably with previous experimental and theoretical information with respect to geometries and other properties where such information is available. The use of effective core potentials (ECPs) to obtain these stationary points lessens the time of computation and gives good results as long as a suitably flexible valence basis set is used. These results should encourage the further use of ECPs for structural problems involving the larger elements.

Much of the discussion concerning the chemistry of transition-metal carbene complexes has been presented in terms of the resonance contributors which describe the metal-carbon bond. Resonance structures which describe the metal-carbon bond can be partitioned into three types-nucleophilic, electrophilic, and neutral. These cases correspond to resonance structures in which the carbene carbon has a negative, positive, and neutral formal charge, respectively. Nucleophilic resonance structures contribute approximately $50 \%$ to the ground-state wave function of the

(93) Tantardini, G. F.; Simmonetta, M. Int. J. Quantum Chem., Proc. Sanibel Symp 1978, 12, 131. alkylidene complexes. Neutral resonance structures account for much of the remainder $(\approx 45 \%)$. Only $5 \%$ of the ground-state wave function of these alkylidene complexes is comprised of electrophilic resonance structures.

The metal carbon double bond in high-valent alkylidenes is predominantly comprised of five resonance structures: $M \div C$, $\mathrm{M}=\mathrm{C}, \mathrm{M}_{\leftarrow} \mathrm{C}, \mathrm{M}^{\leftarrow} \mathrm{C}$, and $\mathrm{M}_{\leftarrow}^{\leftarrow} \mathrm{C}$. Four of these resonance structures correspond to models of carbene bonding which have been discussed previously in the literature; the fifth resonance structure $(\mathrm{M}-\mathrm{C})$ can be described as arising from a dative carbon-to-metal $\sigma$ bond coupled with a covalent $\mathrm{M}-\mathrm{C} \pi$ bond and amounts to one-third of the ground-state wave function. Thus, there are several major resonance contributors to the electronic structure of these compounds.

The results of the present research point to a description of the $\mathrm{M}-\mathrm{C} \pi$ bond in the high-valent, alkylidene complex that is more covalent than is commonly appreciated. Resonance structures in which the $\mathrm{M}-\mathrm{C} \pi$ bond is covalent contribute over two-thirds to the ground state of these complexes. The $\mathrm{M}-\mathrm{C} \sigma$ bond can be more accurately described as a dative bond.

Acknowledgment. This work was supported in part by grants from the National Science Foundation (CHE89-11911) and the Air Force Office of Scientific Research (90-0052). The calculations described herein were carried out on a DECstation 3100 (funded by a grant from the NSF) and the NDSU IBM 3090$200 \mathrm{E}$ (purchased in part by a joint study agreement with IBM). The authors wish to thank Dr. Michael W. Schmidt (NDSU) for helpful discussions and Walter Stevens, Morris Krauss, and Paul G. Jasien (NIST) and Harold Basch (Bar Ilan University) for providing us with their ECPs prior to publication. The authors also gratefully acknowledge the assistance of Prof. Richard R. Schrock (MIT) for providing us with a copy of ref $79 \mathrm{~b}$ before its publication. The help of Alan S. Goldstein and Shaun O. Sommerer (University of Florida) in providing background material is also gratefully acknowledged. 